\title{
Engineering Assessment of $\mathrm{UO}_{2}$ and Cladding Behavior under High- Burnup LOCA Conditions
}

Nuclear Technology

Research and Development

Prepared for

U.S. Department of Energy

Nuclear Energy Advanced Modeling and Simulation

Nathan Capps, ${ }^{1}$ Ryan Sweet ${ }^{1}$, Jason Harp ${ }^{1}$, and Christian Petrie ${ }^{1}$

1Oak Ridge National Laboratory

September 2021

M3MS-21OR0201041 



\section{DISCLAIMER}

This information was prepared as an account of work sponsored by an agency of the U.S. Government. Neither the U.S. Government nor any agency thereof, nor any of their employees, makes any warranty, expressed or implied, or assumes any legal liability or responsibility for the accuracy, completeness, or usefulness, of any information, apparatus, product, or process disclosed, or represents that its use would not infringe privately owned rights. References herein to any specific commercial product, process, or service by trade name, trade mark, manufacturer, or otherwise, does not necessarily constitute or imply its endorsement, recommendation, or favoring by the U.S. Government or any agency thereof. The views and opinions of authors expressed herein do not necessarily state or reflect those of the U.S. Government or any agency thereof. 



\section{ACKNOWLEDGMENTS}

This work was supported by the Advanced Fuels Campaign of the US Department of Energy Office of Nuclear Energy. The authors would like to express appreciation to Jake Hirschhorn and Caleb Massey (Oak Ridge National Laboratory) for their support in the review of this manuscript. 


\section{SUMMARY}

To maximize the data extracted from a limited number of high-burnup fuel rod samples, several modeling efforts were performed to elucidate the fuel and the cladding responses of these fuels under transient conditions. These objectives were (1) to determine the role of the fuel stress state in fuel pulverization, (2) to ascertain the differences between conditions of cladding burst during experiments and those expected during a commercial reactor transient, and (3) to develop a method to conservatively calculate the geometry of the cladding rupture's opening to inform fuel dispersal susceptibility. 


\section{CONTENTS}

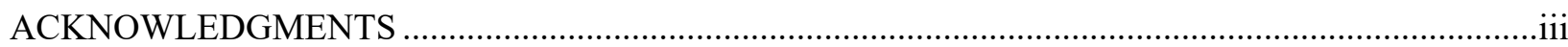

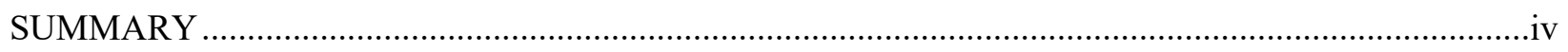

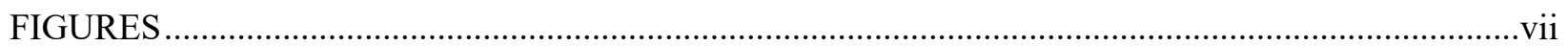

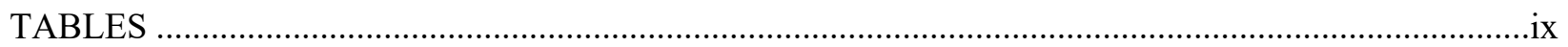

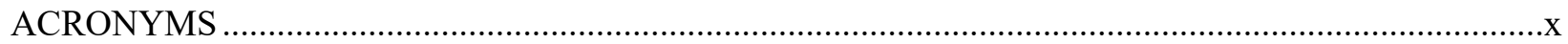

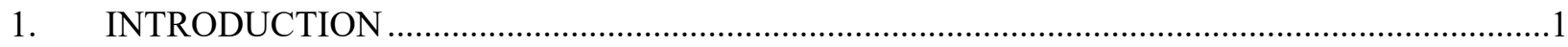

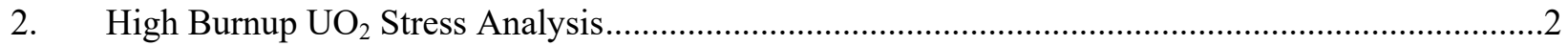

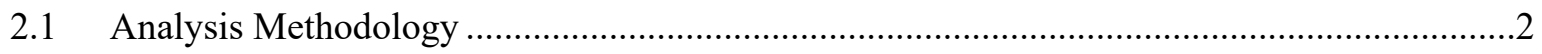

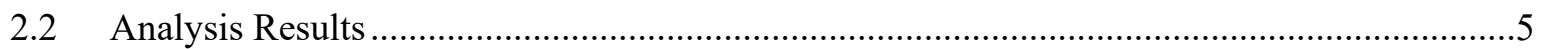

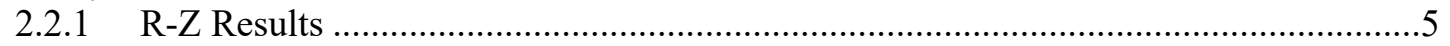

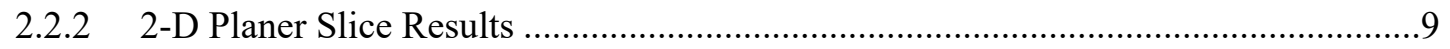

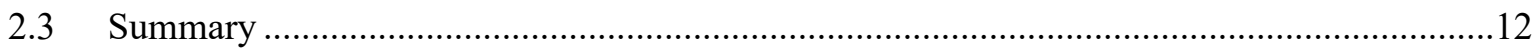

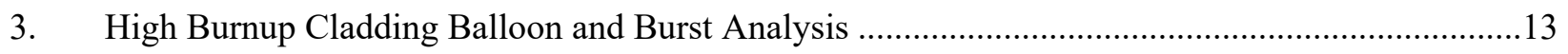

3.1 Commercial Fuel Rod Cladding Burst Evaluation Method ................................................13

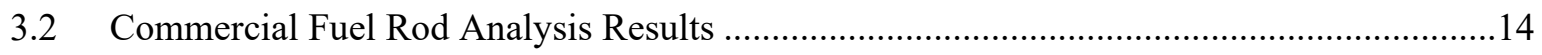

3.3 Cladding Burst Tube Evaluation and Experimental Development .....................................22

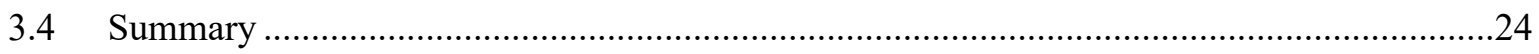

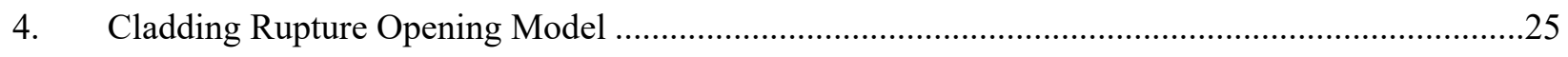

4.1 Literature Review: Experimental Data Summary ….......................................................25

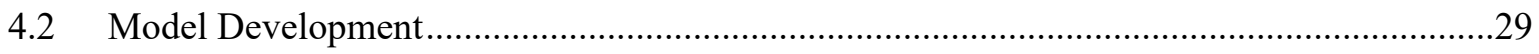

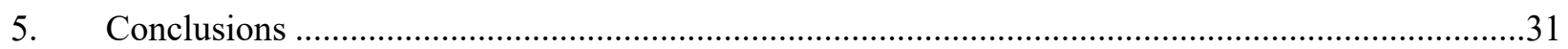

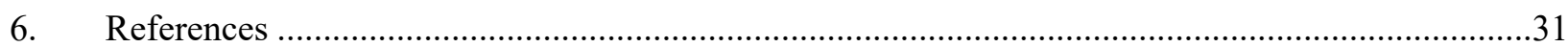


FIGURES

Fig. 1. (a) Steady-state LHR and LHR at the burst location (red-dotted line) and (b) post scram decay heat at the burst location as a function of time for a high-burnup fuel rod from a realistic high burnup core design [25].

Fig. 2. Cladding temperature at the burst location and coolant pressure during the LOCA transient [25].

Fig. 3. (a) BISON planer slice model with quarter symmetry and (b) ANSYS planer slice model of a wedge with $\mathrm{N}=8$ radial cracks and a single circumferential crack. 4

Fig. 4. Pre-transient R-Z fuel conditions prior to a simulated LOCA transient. 6

Fig. 5. R-Z fuel response during a simulated LOCA transient: (a) radial temperature, (b) radial stress, (c) axial stress, and (d) hoop stress. Note the end of the blowdown phase and the start of the refill phase occurs at $27 \mathrm{~s}$.

Fig. 6. Cladding surface temperature at the burst location for a case with and without a blowdown.

Fig. 7. Comparison of the blowdown and no blowdown fuel temperature and hoop stress profiles in R-Z space at $27 \mathrm{~s}$ after LOCA initiation.

Fig. 8. Planer slice fuel (a) radial, (b) hoop, (c) axial stress along the $\mathrm{x}$-axis as a function of pretransient LHR (i.e., temperature) with no radial cracks.

Fig. 9. Planer slice fuel (a) radial and (b) hoop stress along the $\mathrm{x}$-axis as a function of burnup with no radial cracks.

Fig. 10. a) ANYSIS calculated maximum tensile stresses ( $\sigma \max )$ after reaching a uniform pellet temperature with a pre-transient LHR of $24 \mathrm{~kW} / \mathrm{m}$, and b) BISON power ramp to power analysis .....

Fig. 11. PCT for the blowdown vs. no blowdown thermal boundary condition.

Fig. 12. Analysis assessing the impact of blowdown vs. an event where blowdown is not considered.

Fig. 13. Evaluating the impact of (a) burst temperature as a function of heating rate and constant pre-transient rod internal pressure and (b) burst strain as a function of burst temperature and pre-transient rod internal pressure using the more conservative stress-based burst conditions.

Fig. 14. REBEKA 2 axial power profile [56, 55].

Fig. 15. REBEKA 2 temperature at the burst location [56, 55].

Fig. 16. REBEKA 2 Experimental peaking factor compared with peaking factors calculated by RELAP5-3D for a high-burnup commercial fuel rod [56, 25].

Fig. 17. Comparison between REBEKA 2 and RELAP HBu LOCA axial temperature profiles $[56,25]$.

Fig. 18. Cladding temperature peaking factors as a function of time for (a) high burnup ( $\sim 72 \mathrm{GWd} / \mathrm{tU}$ rod average) and (b) low burnup ( $\sim 40 \mathrm{GWd} / \mathrm{tU}$ rod average) [25].

Fig. 19. Axial temperature profiles from Zry4-21 (red) and for the LWR (blue) simulation. .23

Fig. 20. Cladding rupture temperature and stress for rodlet using measured experiment conditions (red) and LWR-like temperature gradient (blue). 
Fig. 21. Cladding burst area as a function of post-LOCA hoop strain [58-80]

Fig. 22. Cladding burst length as a function of post-LOCA hoop strain [58-80]

Fig. 23. Cladding a) burst width and b) normalize burst width (burst width / cladding outside diameter) as a function of burst length [58-80] .28

Fig. 24. Comparison of cladding rupture length as a function of peak cladding hoop strain for available literature data and average and limiting models.

Fig. 25. Comparison of cladding rupture width as a function of rupture length for available literature data and average and limiting models.

Fig. 26. Comparison of cladding rupture area as a function of peak cladding hoop strain for available literature data and (a) limiting and (b) average models. 


\section{TABLES}

Table 1 Summary of the BISON Models and Associated References....................................................2

Table 2. Full-length fuel rod heating rates and pre-transient pressure conditions.....................................14

Table 3. Burst conditions comparison for the blowdown and no blowdown event...................................16

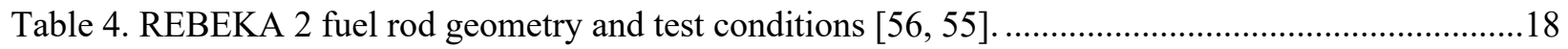

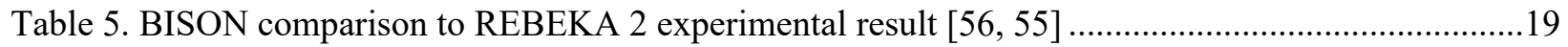

Table 6. BISON results evaluating the impact of axial cladding temperature profile on cladding

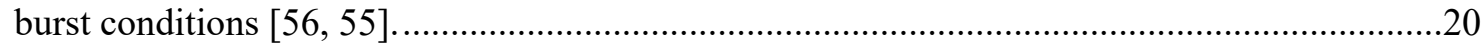

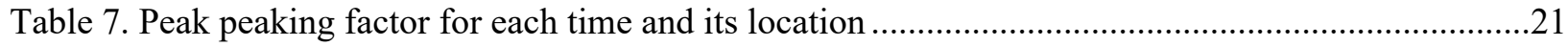

Table 8. Summary of the cladding burst conditions for the experiment and BISON simulation ...............23

Table 9. Fitting constants derived from literature data to determine burst length as a function of peak hoop strain

Table 10. Fitting constants derived from literature data to determine burst opening width as a function of burst length 


\section{ACRONYMS}

$\begin{array}{ll}\text { ECCS } & \text { emergency core cooling system } \\ \text { ECR } & \text { equivalent cladding reacted } \\ \text { FFRD } & \text { fuel fragmentation, relocation, and dispersal } \\ \text { FSAR } & \text { fuel safety analysis report } \\ \text { HBWR } & \text { Halden Boiling Heavy Water Reactor } \\ \text { JFNK } & \text { Jacobian-free Newton-Krylov } \\ \text { LB } & \text { large break } \\ \text { LOCA } & \text { loss-of-coolant accident } \\ \text { LWR } & \text { light-water reactor } \\ \text { MOOSE } & \text { Multi-Physics Object-Oriented Simulation Environment } \\ \text { MT } & \text { material test } \\ \text { NFIR } & \text { Nuclear Fuel Industry Research } \\ \text { NRC } & \text { US Nuclear Regulatory Commission } \\ \text { NRU } & \text { National Research Universal } \\ \text { OECD } & \text { Organisation for Economic Co-operation and Development } \\ \text { ORNL } & \text { Oak Ridge National Laboratory } \\ \text { PCT } & \text { peak clad temperature } \\ \text { PWR } & \text { pressurized water reactor } \\ \text { SATS } & \text { Severe Accident Test Station }\end{array}$




\section{ENGINEERING ASSESSMENT OF $\mathrm{UO}_{2}$ AND CLADDING BEHAVIOR UNDER HIGH-BURNUP LOCA CONDITIONS}

\section{INTRODUCTION}

The nuclear industry is actively developing a technical basis to support extending the peak rod average burnup from 62 to $\sim 75 \mathrm{GWd} / \mathrm{tU}$. However, high-burnup fuel fragmentation, relocation, and dispersal (FFRD) has been identified as one major technical issue that must be addressed prior to extending burnup. To address this issue, the industry is pursuing two different licensing approaches in parallel: (1) a riskinformed approach, and (2) a fuel dispersal consequence analysis. The first approach would render a large-break (LB) loss-of-coolant accident (LOCA) as not being a credible accident scenario because the risk for the accident is below an acceptable level. Furthermore, the risk-informed approach would then show that intermediate and small-break LOCAs do not result in cladding failure, and therefore, it would show that FFRD is a not a safety issue of concern for high-burnup fuel. The LB LOCA approach assumes that cladding failure does occur and will likely require the industry to use best-estimate tools to calculate fuel rod failure, pulverized $\mathrm{UO}_{2}$ mass, and fuel dispersal. Both approaches have their merits, and success will likely hinge on the use of both approaches to successfully disposition FFRD as a safety concern. However, both approaches rely on successfully predicting high-burnup fuel performance to assess whether cladding failure occurs, and if so, to assess pulverization and dispersal susceptibility.

Assessing fuel performance under high-burnup conditions requires evaluating steady-state and transient conditions. Therefore, it is critical to assess the ability of the fuel performance code to accurately predict fuel evolution prior to the transient to appropriately set the transient's initial conditions and to evaluate the fuel evolution during the transient. Therefore, the fuel performance code must accurately predict the phenomenon observed in both regimes. Steady-state material models for Zircaloy and $\mathrm{UO}_{2}$ have been benchmarked and validated up to a $62 \mathrm{GWd} / \mathrm{tU}$ rod average burnup, and in some cases, validation has been performed up to pellet average burnups in the low $90 \mathrm{~s} \mathrm{GWd} / \mathrm{tU}$. Therefore, it seems reasonable that steady-state fuel conditions would be applicable to $75 \mathrm{GWd} / \mathrm{tU}$ when assessing fundamental performance. For phenomena such as high-burnup fission gas release and high-burnup structure, the fuel performance code requires additional improvements to accurately predict fuel behavior, but these inadequacies can be addressed by means of evaluating the material model sensitivities to assess drastic changes in fuel performance. The more complicated aspect of this work is to understand the material model behavior under transient conditions, especially at high burnup. Unlike steady-state data, transient data are far more difficult to acquire given the high cost, the lack of material, and the lack of facilities that conduct these types of tests. Steady-state operation has been highly characterized and assessed since the inception of commercial nuclear power, but a tremendous amount of effort has been put for to prevent transients and accidents from occurring. This approach has been widely successful, and because of this success, there is no consensus regarding the definition of a prototypic transient. Separate effects testing has been leveraged as much as possible, but gaps and questions remain. Therefore, it is critical to connect commercial transient fuel rod analysis back to experimental data as appropriate, and if differences exist, then the analysis results can be used to improve subsequent experimental efforts.

This milestone report supports the industry's safety case by evaluating those conditions for which FFRD is impacted and informing subsequent FFRD-related experiments and modeling research activities. This objective is to address the differences between electrically heated inferred LOCA testing vs. heating tests reliant on nuclear heating. Furthermore, transient performance of cladding will be considered to inform the no burst criteria, and a cladding burst model will be developed to better inform fuel dispersal susceptibility. 


\section{High Burnup $\mathrm{UO}_{2}$ Stress Analysis}

\subsection{Analysis Methodology}

The BISON fuel performance code was used for the LOCA simulations described herein based on previous validation of the code for light-water reactor (LWR) applications [1-3]. BISON was built on the Multi-Physics Object-Oriented Simulation Environment (MOOSE) framework, which is a parallel finite element computational system [4]. MOOSE uses the Jacobian-free Newton-Krylov (JFNK) method to solve fully coupled systems of nonlinear partial differential equations. In addition, BISON can be parallelized to perform high-fidelity modeling of fuel rods in three dimensions, as well as in full-length R$\mathrm{Z}$ and planer slice geometries. BISON has been extensively validated to both LWR steady-state [5] and transient [6] integral tests. The models used for these validation efforts are well documented [5,6], as are the implementations of these models in BISON [7]. Table 1 summarizes the models used in BISON analysis, as well as the associated references.

Table 1. Summary of the BISON models and associated references

\begin{tabular}{|c|c|c|c|c|c|}
\hline \multicolumn{3}{|c|}{ Fuel } & \multicolumn{3}{|c|}{ Cladding } \\
\hline Property & Model & Reference & Property & Model & Reference \\
\hline $\begin{array}{c}\text { Thermal } \\
\text { conductivity }\end{array}$ & NFIR & {$[8,9]$} & $\begin{array}{c}\text { Thermal } \\
\text { Conductivity }\end{array}$ & Fink & [17] \\
\hline $\begin{array}{c}\text { Elastic } \\
\text { properties }\end{array}$ & MATPRO & [10] & $\begin{array}{c}\text { Elastic } \\
\text { Properties }\end{array}$ & MATPRO & [10] \\
\hline Relocation & $\begin{array}{l}\text { Modified } \\
\text { ESCORE }\end{array}$ & [11] & $\begin{array}{l}\text { Irradiation } \\
\text { Growth }\end{array}$ & Franklin & [18] \\
\hline $\begin{array}{c}\text { Fission gas } \\
\text { release }\end{array}$ & Sifgrs & [12] & $\begin{array}{l}\text { Thermal } \\
\text { Expansion }\end{array}$ & MATPRO & [10] \\
\hline $\begin{array}{l}\text { Thermal } \\
\text { expansion }\end{array}$ & Constant & & $\begin{array}{l}\text { Thermal } \\
\text { Creep }\end{array}$ & $\begin{array}{l}\text { Limback- } \\
\text { Anderson and } \\
\text { Erbacher }\end{array}$ & {$[19,20]$} \\
\hline Creep & $\begin{array}{c}\text { MATPRO- } \\
\text { Halden }\end{array}$ & {$[10,13-15]$} & $\begin{array}{c}\text { Irradiation } \\
\text { Creep }\end{array}$ & Hoope & [21] \\
\hline $\begin{array}{c}\text { Solid } \\
\text { swelling }\end{array}$ & MATPRO & [10] & & & \\
\hline $\begin{array}{l}\text { Gaseous } \\
\text { swelling }\end{array}$ & Sifgrs & [16] & & & \\
\hline
\end{tabular}

Establishing the fuel's irradiation history and the condition of the fuel immediately prior to a LOCA transient is critical for evaluating the fuel behavior during the LOCA (i.e., temperature and stress profiles). For example, gap closure, thermal conductivity degradation, and fission gas release are some of the phenomena that impact fuel rod performance during the temperature transient. To ensure that simulated fuel conditions are consistent with realistic high-burnup operating conditions, this report presents results from previous analyses performed by a utility for a representative core design that targeted 24-month fuel cycles in a 4-loop Westinghouse pressurized water reactor (PWR) with increased enrichment and rod average burnup. VERA [22-24] was used to generate the steady-state conditions (i.e., rod power histories, decay power, and thermal hydraulic and mechanical boundary conditions) for input into the BISON simulations. One fuel rod in particular was selected for BISON R-Z analysis based on its high burnup and its location in the core; the steady-state power history and post-scram decay heat histories are shown in Fig. 1a and 1b, respectively. The LOCA was initiated following the last full power time step, and the decay heat, shown in Fig. 1b, is specific to the burst location. 


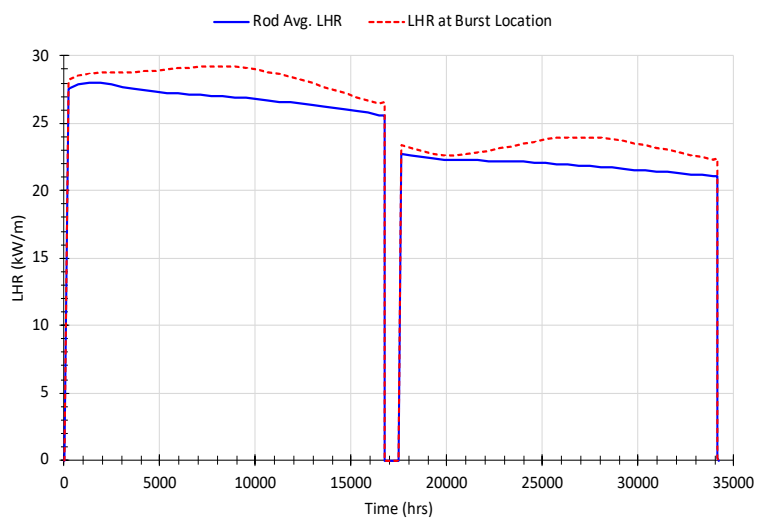

(a)

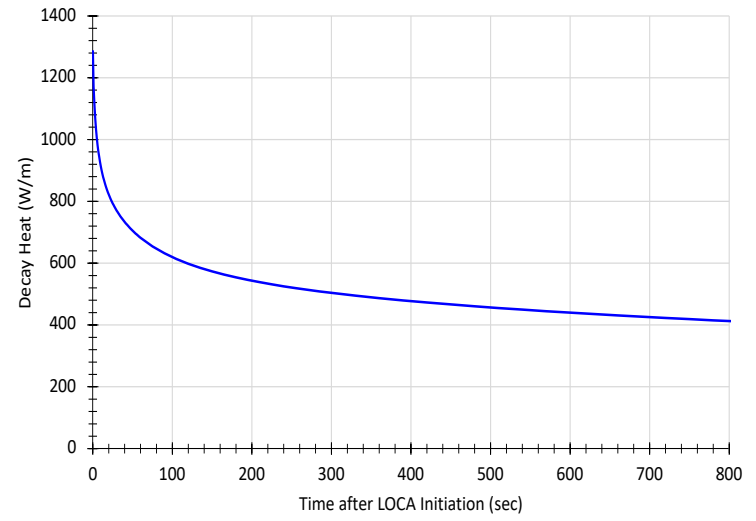

(b)

Fig. 1. (a) Steady-state linear heat rate (LHR) and LHR at the burst location (red-dotted line) and (b) post scram decay heat at the burst location as a function of time for a high-burnup fuel rod from a realistic high burnup core design [25].

The thermal boundary conditions used for the BISON analyses were determined using RELAP5-3D $[25,26]$. Models were based on a 4-loop Westinghouse PWR design and were compared to results from a 4-loop Westinghouse PWR fuel safety analysis report (FSAR) to ensure that the LOCA response and timing were consistent with industry standards. The transient cladding temperature at the burst location (i.e., peak cladding temperature) and the coolant pressure can be seen in Fig. 2. It should be noted that Fig. 2 is a local temperature, and a time-dependent axial temperature profile was applied to the cladding's outer surface during the steady-state irradiation and the LOCA transient. Annotations in Fig. 2 indicate the blowdown, refill, and reflood phases of the LOCA progression. The blowdown phase lasts $\sim 25 \mathrm{~s}$ and promptly transitions to the refill phase. The cladding temperature steadily increases during the refill phase until the peak clad temperature (PCT) is reached at $190 \mathrm{~s}$. The cladding temperature is maintained until $\sim 320 \mathrm{~s}$, when the cladding slowly cools as the core begins to refill. The reflood phase can be identified by the rapid cladding temperature drop towards the end of the simulation $(\sim 775 \mathrm{~s})$. In this work, the fuel temperatures and stresses were only evaluated during the blowdown and refill phases, which is when FFRD has typically been observed to occur [36-42,27]. 


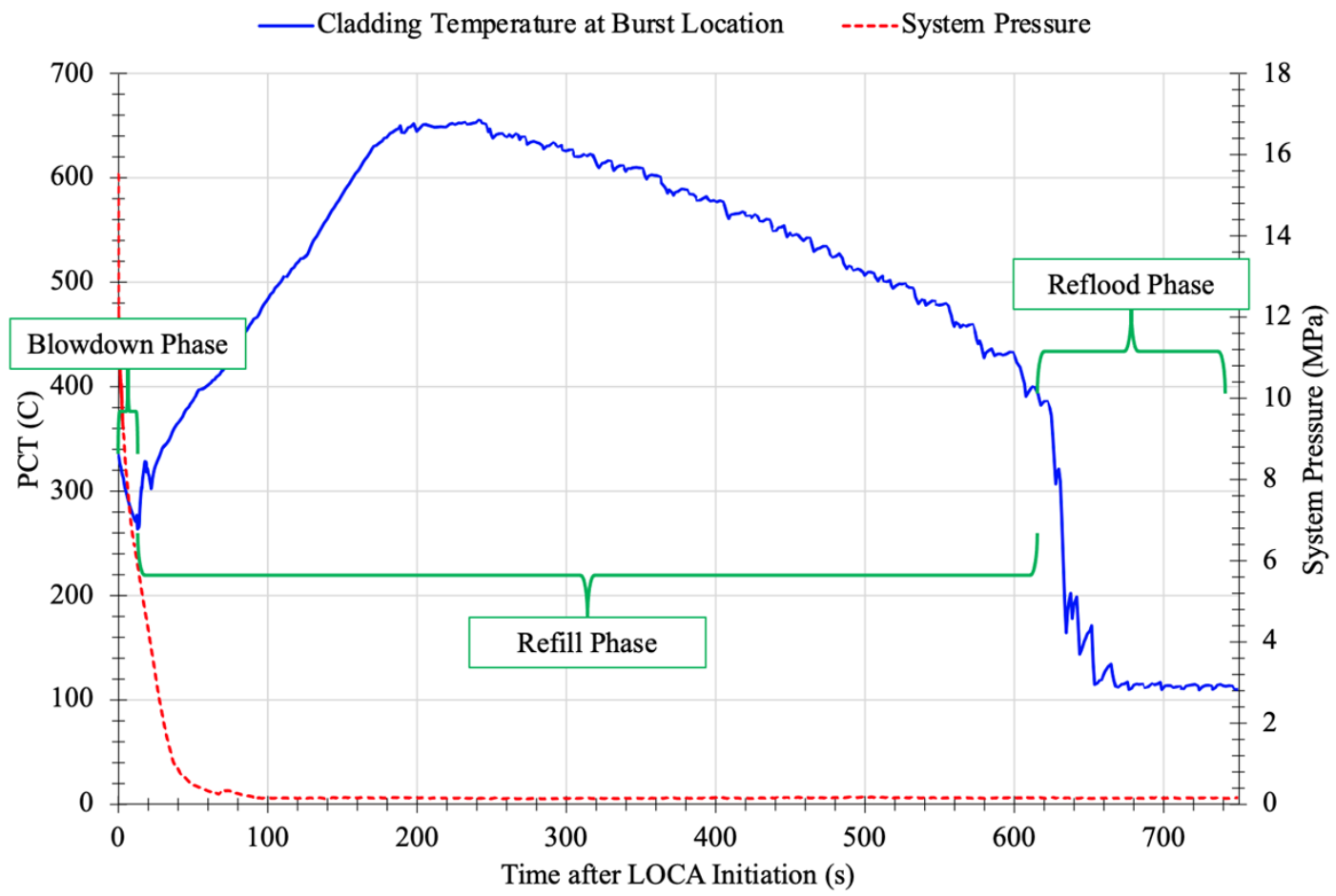

Fig. 2. Cladding temperature (blue) at the burst location and coolant pressure (red) during the LOCA transient [25].

A $90^{\circ}$ symmetric generalized plane strain planer slice BISON model was developed to perform sensitivity studies at a single axial location along the fuel rod. The sensitivity studies were designed to investigate the effect of operating conditions (i.e., burnup and linear heat rate [LHR]) on fuel stresses before and during the LOCA. All transient analyses used the same decay heat history and thermo-mechanical boundary conditions shown in Fig. $1 \mathrm{~b}$ and Fig. 2. The steady-state irradiation power history was held at a constant LHR to allow for better isolation of the fuel pellet temperature conditions prior to the transient. Fig. 3a provides an example of a BISON planer slice model with quarter symmetry.

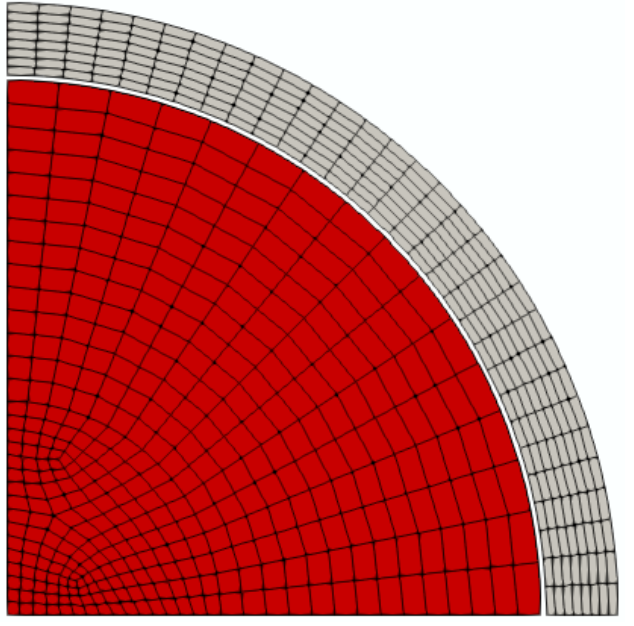

(a)

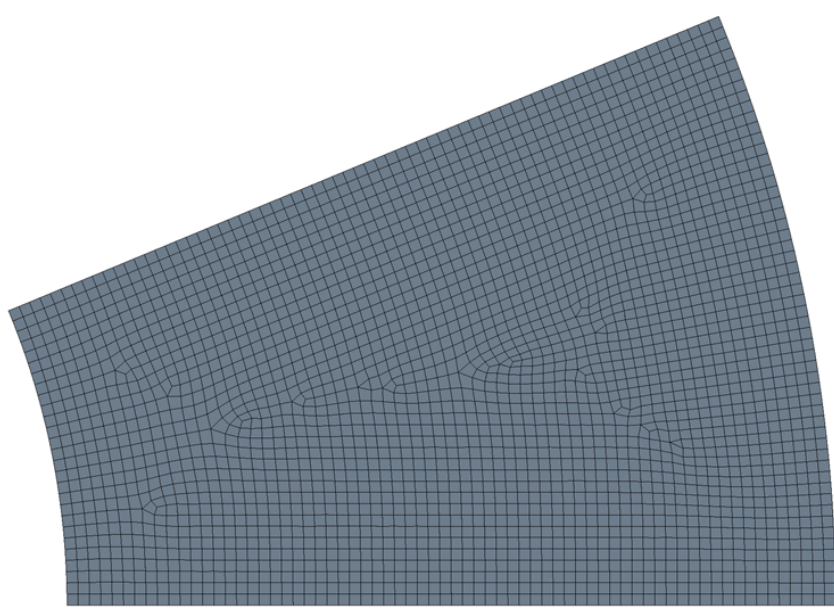

(b)

Fig. 3. (a) BISON planer slice model with quarter symmetry and (b) ANSYS planer slice model of a wedge with $\mathrm{N}=8$ radial cracks and a single circumferential crack. 
Additional planer slice analyses were performed using the ANSYS finite element code to evaluate fuel stresses after introducing full-length radial and circumferential cracks. Previous analyses have shown that radial cracks are initiated at the outer surface of the fuel during the initial ascent to full power operation [30]. Those cracks extend to the center of the pellet after the first shutdown, and additional circumferential cracking may also occur, depending on the operating history and burnup [31]. Instead of modeling discrete cracks, the fuel was divided into a total of $\mathrm{N}$ radial sections (for $\mathrm{N}$ cracks), and only one half of a single wedge was modeled. The effects of circumferential cracking were modeled by setting the inner fuel radius to either $0.1 \mathrm{~mm}$ (essentially equivalent to a wedge without a circumferential crack) or $50 \%$ of the pellet radius. In addition to applying uniform volumetric fission heating across the fuel wedge, a heat flux was applied to the inner surface of the fuel to account for heat generated in the inner fuel wedges, which were not explicitly modeled. The ANSYS simulations fixed the outer fuel surface temperature at $400^{\circ} \mathrm{C}$. Although this may have some impact on the absolute temperatures in the fuel, it does not impact the temperature gradients, which ultimately determine the thermal stresses. The fuel temperatures were used as a boundary condition for structural analyses, which applied circumferential symmetry on one face of each wedge while leaving the opposite face unconstrained. A one-dimensional weak spring $(10 \mathrm{~N} / \mathrm{m})$ element was used to prevent rigid body motion in the radial direction without constraining the wedge.

A previously developed model [32] was used to determine dependence of the thermal conductivity of $\mathrm{UO}_{2}$ on density (assumed $95 \%$ of theoretical), temperature, and burnup. The temperature-dependent thermal expansion and elastic modulus (also density-dependent) also have a weak dependence on burnup because these parameters depend on the solidus temperature [33]. A constant value of 0.316 was used for Poisson's ratio. Fig. 3b shows an example of the mesh used for a case with $\mathrm{N}=8$ and a circumferential crack that is simulated by setting the inner fuel radius to be equal to $50 \%$ of the outer fuel radius.

\subsection{Analysis Results}

\subsubsection{R-Z Results}

\subsubsection{Analysis of Record}

As indicated above, fuel tested in the Halden Boiling Heavy Water Reactor (HBWR) experienced less fragmentation than the fuel with similar burnup tested at Studsvik, which suggests that internal nuclear heating during the LOCA, as opposed to external heating, helped reduce fuel stresses and fuel pulverization. Addressing the differences observed in these experiments requires an understanding of the prototypic fuel conditions (i.e., temperature and stress profile) prior to a LOCA so that differences in the fuel state can be evaluated during the transient. Fig. 4 shows the fuel temperature and stresses as a function of radial position at the burst location for a realistic full length commercial fuel rod simulated to a rod average burnup of $\sim 72 \mathrm{GWd} / \mathrm{tU}$. Fuel cracking was not considered in this evaluation. Results were evaluated at the last full power timestep with an LHR of $\sim 23 \mathrm{~kW} / \mathrm{m}$. The temperature profile (solid red line) is consistent with expectations, as the fuel centerline temperature is $\sim 1,250^{\circ} \mathrm{C}$ with a parabolic shape ending at the pellet periphery with a temperature of $\sim 450^{\circ} \mathrm{C}$. Fuel stresses (radial, axial, and hoop) are also shown in Fig. 4. Pellet stresses are compressive and have a relatively small magnitude that ranges from -30 to $-5 \mathrm{MPa}$. Radial stresses are consistent with the inner portion of the fuel when it is operating at higher temperatures and expanding more than the outer portion, resulting in larger compressive stresses. In addition, pellet-cladding contact results in slight compressive stresses, even at the pellet periphery. Axial and hoop stresses are consistent with constrained thermal expansion, which would normally result in a transition from compressive stresses at the inner (hotter) portion of the pellet and tensile stresses at the outer (cooler) surface. However, pellet-cladding contact introduces additional compressive stresses on the pellet periphery. The complications associated with modeling of steady-state fuel stresses make it difficult to trust the exact magnitude of the calculated stresses. However, the neutrality of the stress is reasonable as creep, hot pressing, plastic flow, and cracking all reduce the fuel stress to a near-stress-free state during steady-state conditions. Perhaps the most important conclusion from the results presented in 
Fig. 4 is that the end-of-life stress state in the fuel is in equilibrium with the end-of-life temperature profile.

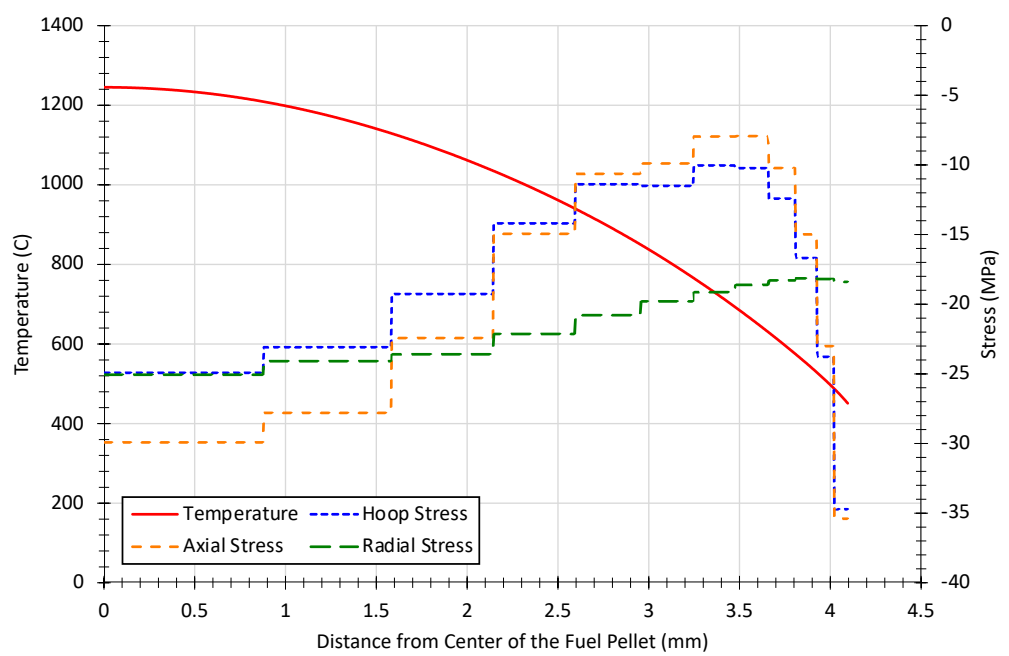

Fig. 4. Pre-transient R-Z fuel conditions prior to a simulated LOCA transient.

Addressing the differences between nuclear and electrical heating requires assessing the fuel temperature and stress evolution from hot full power conditions through the duration of the LOCA. The LOCA event was initiated at the last full power step. Fig. 5 shows the radial temperature and stress profiles (radial, hoop, and axial) as a function of time relative to the start of the transient. The pre-transient results indicated by the solid blue lines are identical to the results shown in Fig. 4. Fuel temperatures (Fig. 5a) begin to decrease shortly after the LOCA initiation. Within $5 \mathrm{~s}$, fuel temperatures fall below $700^{\circ} \mathrm{C}$, and the radial temperature gradient begins to diminish. The blowdown phase ends at $\sim 27 \mathrm{~s}$, at which point the fuel temperatures are minimized with a completely flat profile. The rapid temperature decrease that occurs between 0 and $27 \mathrm{~s}$ results from the rapid reduction in nuclear heating (i.e., fission) while the coolant is still able to sufficiently cool the fuel. Following the blowdown, fuel temperatures begin to steadily increase while maintaining a flat profile. The insufficient heat sink effectively creates an adiabatic thermal boundary condition, which causes the fuel and cladding temperature to uniformly increase due to the decay heat from the rod itself and from the surrounding rods. These results show that the fuel temperature profile is driven entirely by the boundary condition at the cladding outer surface; the decay heat in the fuel is insufficient to cause any significant temperature gradient. Because the radial fuel temperature profile remains flat during a fully nuclear-heated LOCA test after $27 \mathrm{~s}$, the radial temperature profiles are virtually identical for nuclear and electrical heating.

Changes in the fuel temperature and the temperature profile directly impact the fuel pellet stress state. During steady-state operation, the fuel thermally expands under constraint in the radial direction, generating compressive radial stresses and hoop stresses that transition from compression at the center of the pellet to tension at the pellet surface. Over time, fuel creep relaxes these stresses to the point at which the stress reaches an equilibrium with a parabolic temperature gradient. Fig. $5 \mathrm{~b}$ shows how cooling the pellet to a uniform temperature profile under constraint causes the stresses to change. The radial stresses at the pellet's periphery become neutral as the pellet shrinks more than the cladding and is no longer constrained at its surface, thus eliminating pellet-cladding contact. However, the inner portion of the pellet is constrained by its surrounding material, so radial tensile stresses develop as the fuel cools to a uniform temperature, causing it to shrink relative to its equilibrium pre-transient state. This is effectively the reverse of what happens when the reactor first starts up from a uniform temperature. The radial stresses increase in magnitude until the end of the blowdown, when the temperature gradient disappears.

Once the temperature profile becomes flat near $27 \mathrm{~s}$, the radial stress remains unchanged, even as the temperature continues to increase uniformly. This is because the stress is governed by differential thermal 
expansion across the pellet relative to the pre-transient equilibrium state with a parabolic temperature profile. Once the temperature profile becomes flat, the differential thermal expansion across the pellet does not change as the temperature increases uniformly. The slight decrease in radial stresses at $100 \mathrm{~s}$ is a result of stress relaxation once the fuel temperature is high enough to activate thermal creep. Effectively, the physics that govern fuel stresses during reactor startup (commonly discussed when assessing pelletcladding interaction) are the same physics (only in reverse) that cause the fuel stresses to increase during a LOCA. This is an important point, because it indicates that macroscopic stresses generated beyond $27 \mathrm{~s}$ after the initiation of a LOCA are no different than the stresses that would be generated during a normal shutdown after cooling to room temperature.

The axial stress (Fig. 5c) and hoop stress (Fig. 5d) have different profiles resulting from differing constraints. Far away from the top and bottom surfaces of the pellets, the pellets are constrained in both the axial and hoop directions. During steady-state operation under a parabolic temperature profile, constrained thermal expansion puts the pellet interior under compression and the pellet periphery in tension. As seen in the radial stresses, fuel creep reduces these stresses until they reach an equilibrium with the temperature gradient. Removing the temperature gradient during a LOCA transient or reactor shutdown causes the reverse of the stress state that was present during steady-state operation prior to fuel creep. In this case, the stresses transition from tension in the interior of the pellet to compression at the pellet periphery. Hoop and axial stresses peak once the temperature profile becomes flat $(27 \mathrm{~s})$, and they remain unchanged until the fuel temperatures are high enough to activate thermal creep, which reduces the stresses.

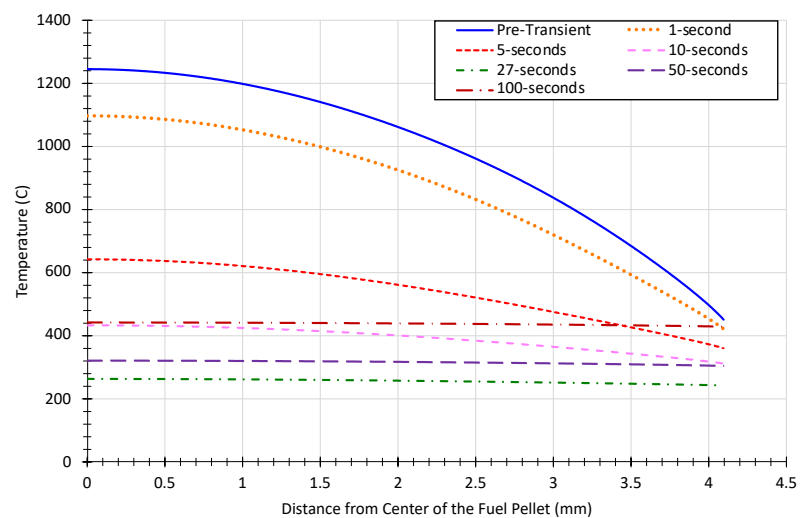

(a)

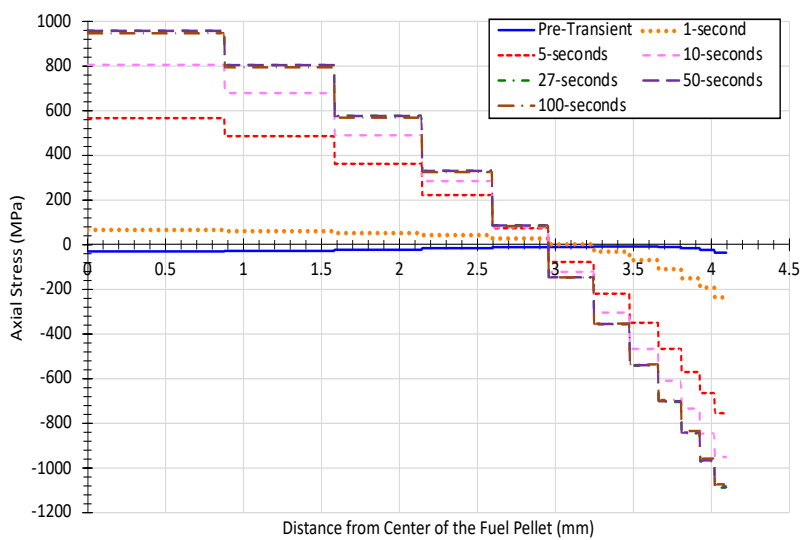

(c)

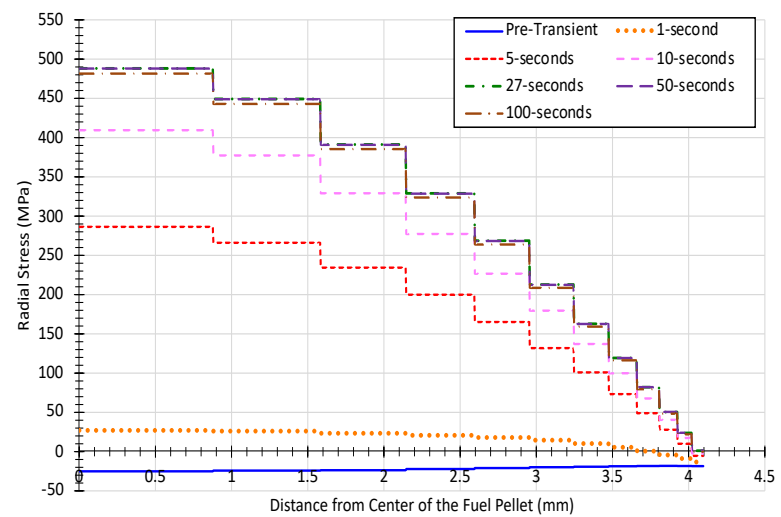

(b)

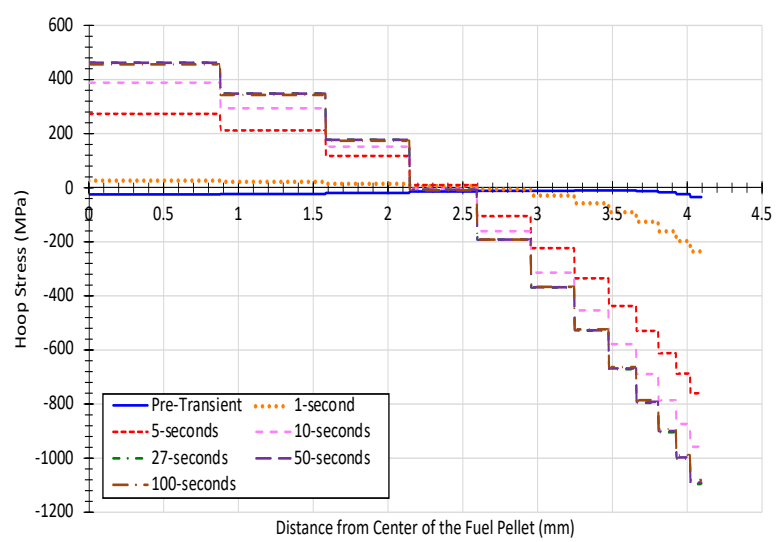

(d)

Fig. 5. R-Z fuel response during a simulated LOCA transient: (a) radial temperature, (b) radial stress, (c) axial stress, and (d) hoop stress. Note that the end of the blowdown phase and the start of the refill phase both occur at $27 \mathrm{~s}$. 


\subsubsection{Impact of Blowdown on Fuel Response}

The previous section describes macroscopic fuel stresses during a LOCA transient, including the blowdown, nuclear heating, and a representative temperature transient - similar to the in-pile LOCA tests previously conducted in HBWR. Many traditional in-cell LOCA tests use infrared lamps to externally heat rodlets at a constant heating rate without simulating the effects of the blowdown on the fuel temperatures during the first $\sim 25 \mathrm{~s}$ of the transient $[40-42,27]$. To evaluate potential differences in the stress profiles during in-cell vs. in-core LOCA tests, a comparative simulation was performed assuming that the cladding surface temperatures immediately increase at a rate of $5^{\circ} \mathrm{C} / \mathrm{sec}$ during the in-cell tests, as shown in Fig. 6. A ramp rate of $5^{\circ} \mathrm{C} / \mathrm{sec}$ was chosen to be consistent with heating rates used in Halden, Studsvik, and at Oak Ridge National Laboratory (ORNL). All other pre-transient fuel conditions and transient boundary conditions were kept identical to those shown in Fig. 4 to ensure that the pre-transient conditions did not impact the results.

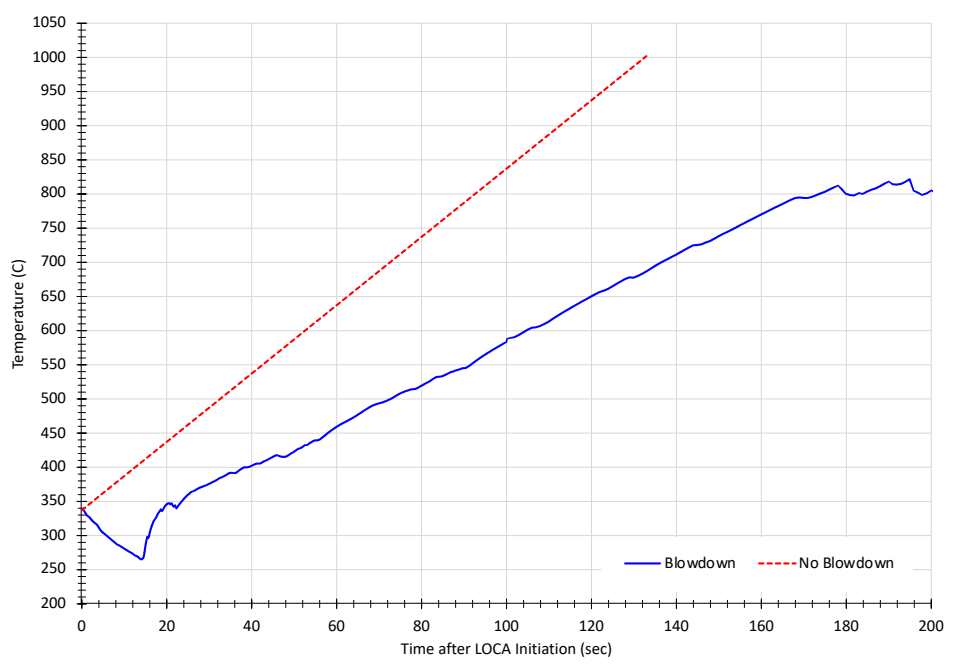

Fig. 6. Cladding surface temperature at the burst location for a case with and without a blowdown.

Fig. 7 shows the BISON results for the two thermal boundary conditions. The results obtained using the blowdown thermal hydraulic boundary condition (shown in blue) are identical to the Fig. 5 results, whereas the results labeled no blowdown (shown in red) were obtained from simulations with a constant cladding temperature starting at time zero. Fuel temperatures from the no-blowdown simulation are noticeably higher than those in which the blowdown was modeled - by $\sim 250^{\circ} \mathrm{C}$ - at the same time during the LOCA. This is a direct result of the cladding heating immediately following LOCA initiation in the no-blowdown case, and a slight difference in ramp rate following the blowdown case. Fig. 7 shows that the fuel temperature profiles are effectively flat for both cases, and the stress profiles are within $5 \%$ of each other at $\sim 27 \mathrm{~s}$ after the LOCA initiation. Stress relaxation mechanisms (i.e., creep, hot pressing, plastic flow, and cracking) reduce fuel stresses to the point at which they are in equilibrium with the pretransient temperature gradient. Removing the temperature gradient by a routine end-of-cycle shutdown or a scram ultimately results in stress being generated in the fuel as a direct result of removing the temperature gradient. In the absence of thermal creep during the transient, the stress profile in the fuel will be the same whether at hot zero power conditions or at any other uniform temperature. As indicated in Fig. 5, fuel stresses start decreasing slightly due to thermal creep once the fuel temperatures reach $\sim 500^{\circ} \mathrm{C}$. Because the temperature profile eventually becomes flat during the LOCA and stresses are essentially fully relaxed prior to the transient, it is the pre-transient fuel conditions that determine the macroscopic thermal stresses generated during the blowdown phase of the LOCA. 


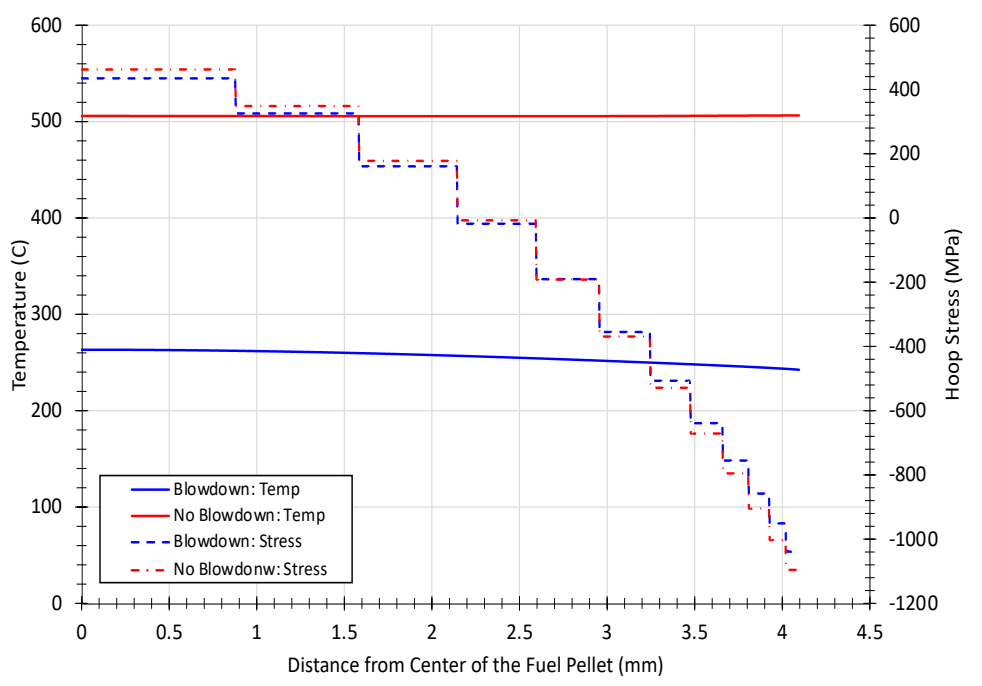

Fig. 7. Comparison of the blowdown and no-blowdown fuel temperature and hoop stress profiles in R-Z space at $27 \mathrm{~s}$ after LOCA initiation.

\subsubsection{D Planer Slice Results}

\subsubsection{Linear Heat Rate and Burnup Sensitivity Studies}

Additional planer slice simulations were performed to evaluate the impact of LHR (i.e., temperature and temperature gradient) on the stresses during a LOCA. The results of these simulations are shown Fig. 8 at the point in time $(27 \mathrm{~s})$ when the temperature profile becomes flat. As indicated in the figure, fuel stresses decrease with decreasing LHR. This result further emphasizes that the stresses generated during a LOCA or a normal shutdown are directly correlated to the fuel temperature and temperature gradient, which establish the equilibrium pre-transient fuel stress profile. Because the fuel stresses depend on differential thermal expansion, the temperature gradient is primarily governed by LHR and the fuel's thermal conductivity, with less dependence on other conditions such as the pellet-cladding gap and fission gas release, which impact the pellet surface temperature and subsequently the temperature-dependent properties of the fuel.
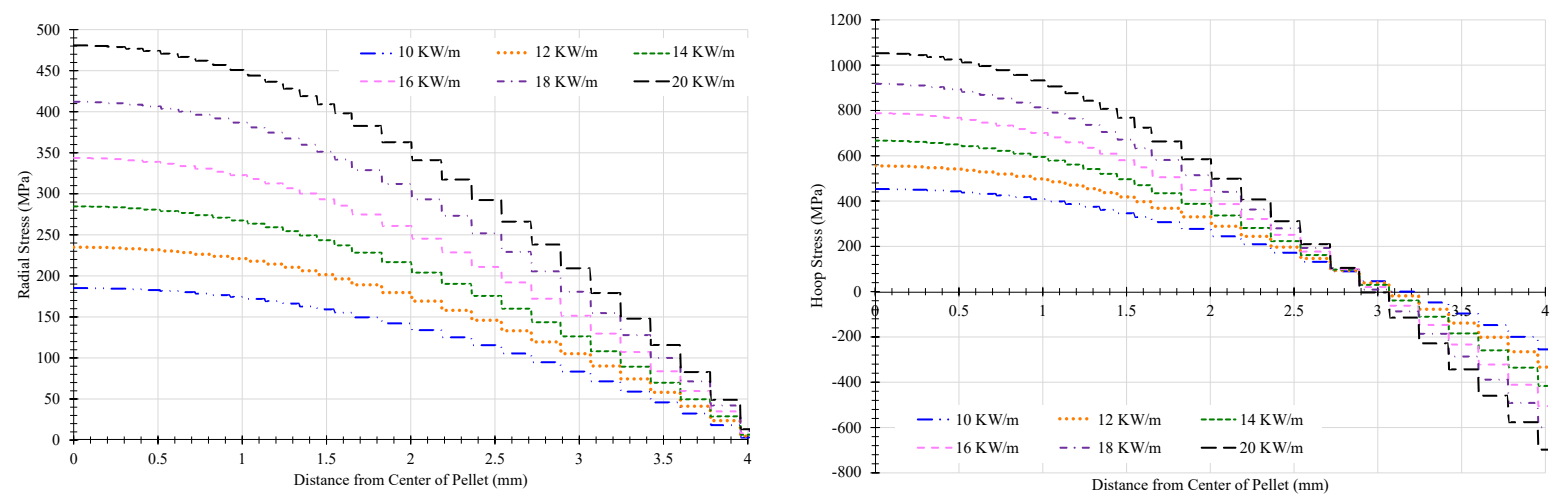

(a)

(b) 


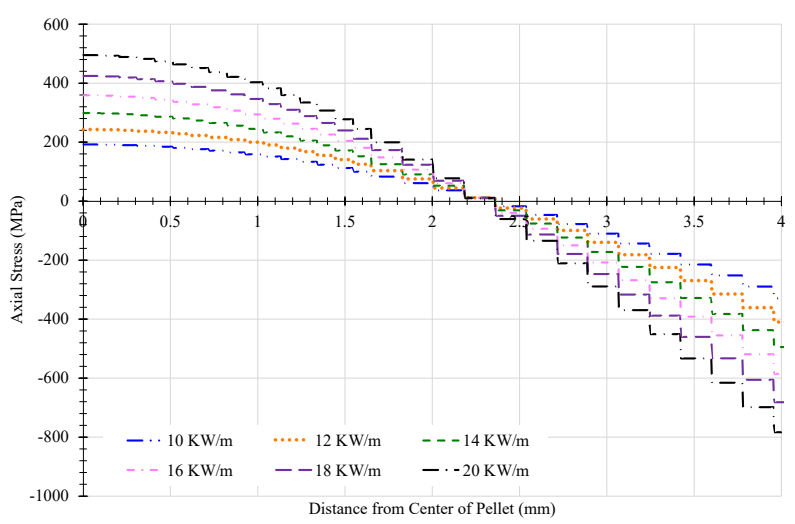

(c)

Fig. 8. Planer slice fuel (a) radial, (b) hoop, (c) axial stress along the $x$-axis as a function of pretransient LHR (i.e., temperature) with no radial cracks.

Differential thermal stresses depend on the pellet's thermal conductivity, which decreases with increasing burnup. Additional simulations were performed to investigate the impact of thermal conductivity degradation to quantify the associated burnup dependence and to ensure that thermal conductivity is the only burnup dependent model that impacts fuel stresses. Each model was identical and consisted of a closed gap to mitigate any temperature changes that may occur as a result of the gap closing. Two simulations incorporated the thermal conductivity model developed by the Nuclear Fuel Industry Research (NFIR) program [34], whereas the other two simulations held the thermal conductivity constant for the entire simulation. Fig. 9 illustrates the burnup- and thermal conductivity-dependent stress results. The stress results shown in Fig. 9 indicate that stresses are impacted by burnup, but when the thermal conductivity is held constant, the stresses remain unchanged as a function of burnup. $\mathrm{UO}_{2}$ thermal conductivity is highly dependent on burnup, and it rapidly degrades as burnup increases [34,35]. The fuel retains additional heat and increases the temperature of the fuel pellet as thermal conductivity degradation occurs. However, when the thermal conductivity is held constant, the fuel can remove heat at the same rate, irrespective of burnup, so the fuel pellet temperature and temperature gradient are held constant. In essence, fuel stresses generated during a LOCA are a direct response of the pre-transient fuel conditions. This response is observed in Fig. 4, Fig. 5, Fig. 8, and Fig. 9, all of which clearly indicate that fuel stresses generated during the LOCA are a result of the pre-transient temperature profile evolution during the LOCA, ultimately resulting in differential thermal contraction of the fuel pellet.

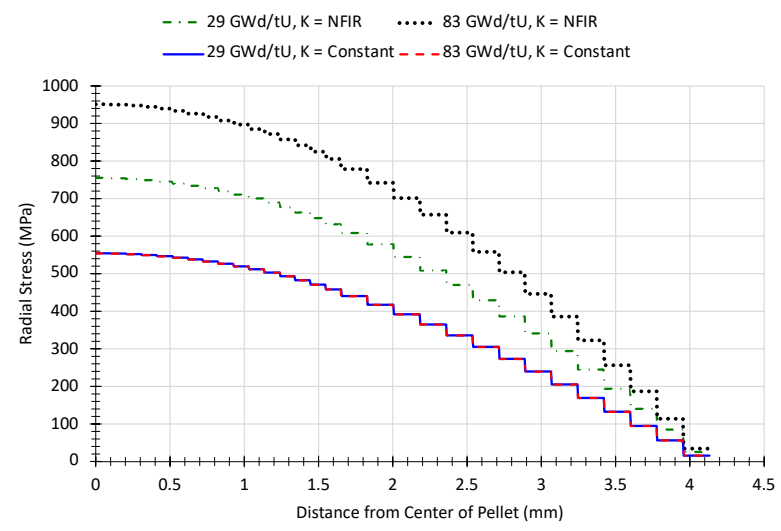

(a)

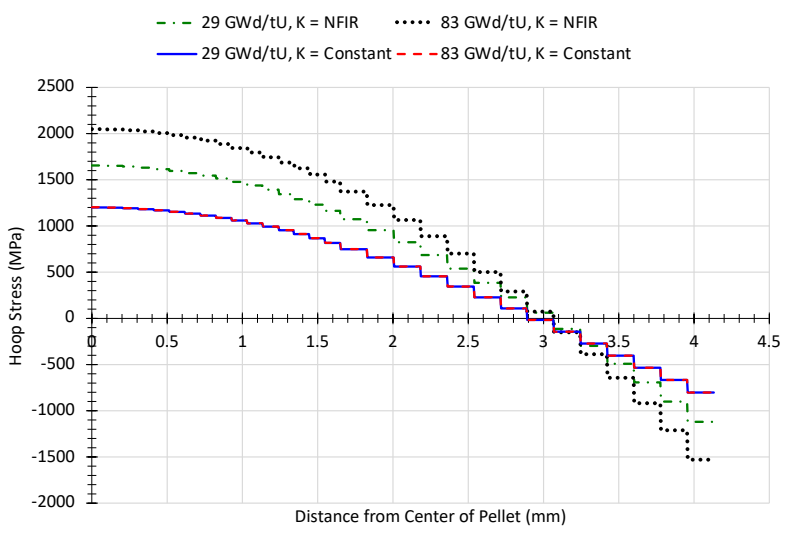

(b)

Fig. 9. Planer slice fuel (a) radial and (b) hoop stress along the $\mathbf{x}$-axis as a function of burnup with no radial cracks. 


\subsubsection{Fuel Fragment Size Characterization Using ANSYS}

The BISON results presented to this point have predicted stresses that greatly exceed typical $\mathrm{UO}_{2}$ fracture stresses, which have been reported to range from 80-150 MPa [29,30]. Experimental data [36-42,27] also show fuel cracking before transient testing and significant cracking and pulverization after transient testing of high burnup fuel. Therefore, cracking will occur prior to the transient and will impact the stress state in the pellet fragments because the cracks change the pellet's constraints. The BISON simulations showed that the pre-transient stresses are essentially in equilibrium with the parabolic temperature profile prior to the transient. Based on these findings, ANSYS simulations were performed without directly simulating the stress relaxation process. Instead, the reference temperatures for thermal expansion were set equal to the pre-transient temperatures for each element. The stresses that would be expected once the fuel temperatures become uniform (i.e., at the end of the blowdown phase of a LOCA transient or a normal shutdown) were then determined by performing a steady-state structural analysis while applying a uniform pellet temperature of $400^{\circ} \mathrm{C}$. The previous BISON results showed that uniform temperature increases during the transient had no significant impact on the fuel stresses. Therefore, the magnitude of the applied uniform temperature is not important. ANSYS simulations were performed with an end-of-life LHR of $30 \mathrm{~kW} / \mathrm{m}$ to maximize fuel stresses. Simulations were performed for $\mathrm{N}=4,8$, and 12 radial cracks. These simulations were performed with the inner fuel radius set to $0.1 \mathrm{~mm}$ to simulate no circumferential cracking, and $50 \%$ of the pellet outer radius to simulate a single circumferential crack. These cases were evaluated for burnups ranging from 50 to $80 \mathrm{GWd} / \mathrm{tU}$.

Fig. 10 shows the ANSYS results without a circumferential crack (red curves) and with a circumferential crack (blue curves). As indicated in the figure legends, the radial stresses are shown with solid lines and diamond markers, and the hoop stresses are shown with dashed lines and + markers. The plotted stresses are the maximum tensile stresses $\left(\sigma_{\max }\right)$ over the entire wedge. The geometries shown in the left column also indicate the fragment size for each case. A range is given for fragments with a significant aspect ratio.

Oguma [30] estimates that for an LHR of $30 \mathrm{~kW} / \mathrm{m}$, the fuel pellet would be expected to form 4 radial cracks and a circumferential crack. The results shown in the top right-hand corner of Fig. 10a indicate that transient stresses would be well below the fracture stress of $\mathrm{UO}_{2}$, so the fuel would not be expected to fracture any further. Because the fracture process is stochastic, the number of cracks may vary from pellet to pellet. Nevertheless, only the case with $\mathrm{N}=4$ and no circumferential cracking resulted in stresses within the $80-150 \mathrm{MPa}$ range for the fracture stress of $\mathrm{UO}_{2}$. If this geometry were to crack in both the radial and hoop directions, then the resulting stresses would be similar to those shown for $\mathrm{N}=8$ and a circumferential crack, which are well below the $\mathrm{UO}_{2}$ fracture stress. These results suggest that once the fragment size becomes small enough (less than $\sim 4 \mathrm{~mm}$ ), there is no longer a macroscopic driving force (i.e., constrained thermal expansion) for continued cracking. Therefore, differential thermal stresses cannot cause the fuel to fragment into wedges smaller than $\sim 4 \mathrm{~mm}$. This effectively disputes theories suggesting that macroscopic stresses induced by changes in the temperature gradient during a LOCA can cause pulverization.

BISON was used to perform a similar analysis on fresh $\mathrm{UO}_{2}$ in which the power was ramped from 0 to 30 $\mathrm{kW} / \mathrm{m}$ (Fig. 10b). The comparison between the two codes is almost identical, confirming that the pretransient power conditions are responsible for generation of larger fragments. The results also clearly show that the pre-transient operating conditions will not generate enough macroscopic stress to pulverize the material, suggesting that microscopic features are attributed to $\mathrm{UO}_{2}$ pulverization. Finally, both BISON and ANSYS results show a very weak burnup dependence on LOCA stresses for all simulations. This further suggests that pulverization of high-burnup fuel is not caused by macroscopic thermal stresses that arise during the transient. 


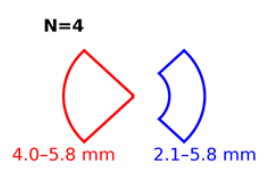

$\mathbf{N}=\mathbf{8}$

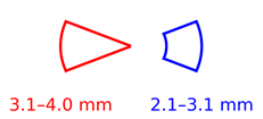

$\mathbf{N}=12$

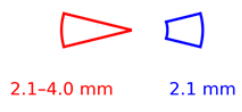

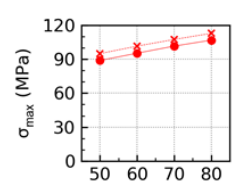
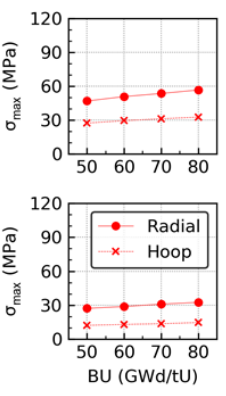

(a)
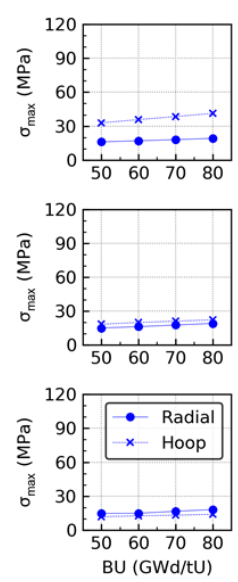

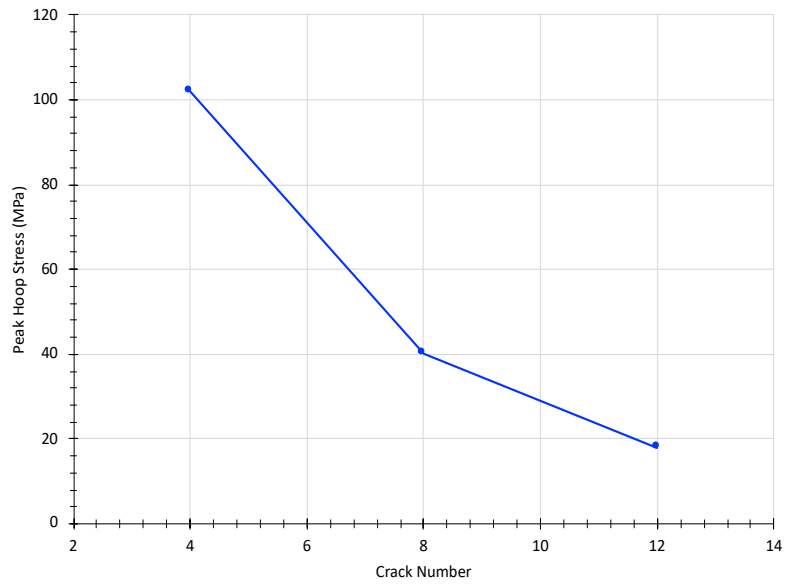

(b)

Fig. 10. (a) ANYSIS calculated maximum tensile stresses ( $\sigma \mathrm{max})$ after reaching a uniform pellet temperature with a pre-transient LHR of $24 \mathrm{~kW} / \mathrm{m}$, and (b) BISON power ramp to power analysis

\subsection{Summary}

Fuel pellet temperatures and stresses were calculated prior to a LOCA and during the transient. Fuel temperatures reached minimum values with a completely flat profile at the end of the blowdown phase of the LOCA. Additional analyses addressed the possibility that immediate heating of the fuel rod might occur at the onset of the LOCA. Fuel temperatures from this hypothetical scenario were noticeably higher than those calculated with the blowdown included; however, the fuel stress profiles were effectively identical. These analyses concluded that the fuel pellet stress is governed by differential thermal expansion across the pellet relative to the pre-transient equilibrium state, and once the temperature profile becomes flat, the differential thermal expansion across the pellet does not change as the temperature increases uniformly. This has important implications, because it suggests that macroscopic stresses $\sim 27 \mathrm{~s}$ after the initiation of a LOCA test would be the same as those following a normal shutdown. LHR and burnup sensitivity studies were performed to determine the primary cause for the macroscopic stress formation. LHR was shown to be directly correlated to the stresses induced during the blowdown phase of the LOCA, and burnup had no effect on fuel stresses. This behavior confirms that macroscopic fuel stresses generated during a LOCA are directly correlated to the pre-transient operating conditions (i.e., LHR), and it also confirms that LOCA heating conditions (e.g., decay heat or external heat) have no impact on the formation of macroscopic stresses.

Additional analyses were performed by modeling unconstrainted wedges of fuel to simulate the effects of cracking on fuel stresses. Comparing the calculated stresses to previously reported fracture stresses for fresh $\mathrm{UO}_{2}$ shows that, for a LHR of $24 \mathrm{~kW} / \mathrm{m}$, the pellet would crack into fragments ranging from 2.1-5.8 $\mathrm{mm}$. This fragment size is well below the fine fragmentation $(<1 \mathrm{~mm})$ that was observed previously during LOCA testing of high-burnup $\mathrm{UO}_{2}$. Once the fragment size was reduced below $\sim 4 \mathrm{~mm}$, the macroscopic driving force for continued cracking would no longer be present. While there are no data regarding the fracture stress or fracture toughness of high-burnup $\mathrm{UO}_{2}$ to offer a more realistic assessment of fragment size, previous observations of high-burnup $\mathrm{UO}_{2}$ have confirmed that pulverization does not occur prior to a LOCA test. Because the calculated fuel stresses were found to be the same following a normal shutdown vs. $>27 \mathrm{~s}$ after the start of a LOCA, the fracture stress of high-burnup $\mathrm{UO}_{2}$ must be high enough to prevent fine fragmentation that results from differential thermal stresses after cooling to room temperature. The culmination of these results unequivocally disputes hypotheses suggesting that the amount of fuel pulverization observed during furnace-style integral LOCA tests are excessive and inflated as a result of thermally induced stresses arising in the fuel from non-prototypic heating conditions. The 
results also imply that the mechanisms driving pulverization during LOCA testing of high-burnup $\mathrm{UO}_{2}$ must be driven by phenomena other than thermal gradient-induced stresses.

\section{High Burnup Cladding Balloon and Burst Analysis \\ 3.1 Commercial Fuel Rod Cladding Burst Evaluation Method}

The analyses will leverage the BISON fuel performance code. BISON has been extensively validated for LWR operating conditions, and more specifically, the code's LOCA capabilities were documented in Williamson et al. [47]. The culmination of these validation efforts supports the application of cladding performance and burst evaluation data to commercial fuel rods. Methods used for commercial fuel rod applications will build on previous high-burnup LOCA efforts and will use the high-burnup fuel rod operating conditions reported in Capps et al. [25]. The fuel rod operating conditions will remain consistent with those reported in Capps et al. [25] except for the blowdown phase, heating rates, and pretransient rod internal pressures. These conditions will be modified to develop an operation envelope that encompasses conditions that might be observed during a LOCA event.

The blowdown phase of the LOCA occurs between the cold-leg rupture (i.e., $t=0 \mathrm{~s}$ ) and the time at which the primary system pressure decreases to near atmospheric pressures. One attribute of the blowdown phase is the ability for the coolant to continue cooling the fuel while being evacuated through the ruptured cold leg. However, one could conservatively assume that the blowdown phase might not occur, which would result in an immediate increase in cladding temperature. This would ultimately result in additional conservatism, because the emergency core cooling system (ECCS) would have less time to reduce the cladding temperature. This conservatism would effectively ensure that the PCT remains below $1,204^{\circ} \mathrm{C}$, but it does not necessarily consider the impact on cladding deformation and burst. Fig. 11 shows an example for each of the two cladding temperature responses: the PCT boundary conditions for a simulation that considers the blowdown, and a simulation that does not consider the blowdown. The impact of various pre-transient pressure and heating rates will also be considered under both thermal hydraulic conditions. Table 2 summarizes the simulation matrix used to evaluate cladding performance and burst under high-burnup conditions.

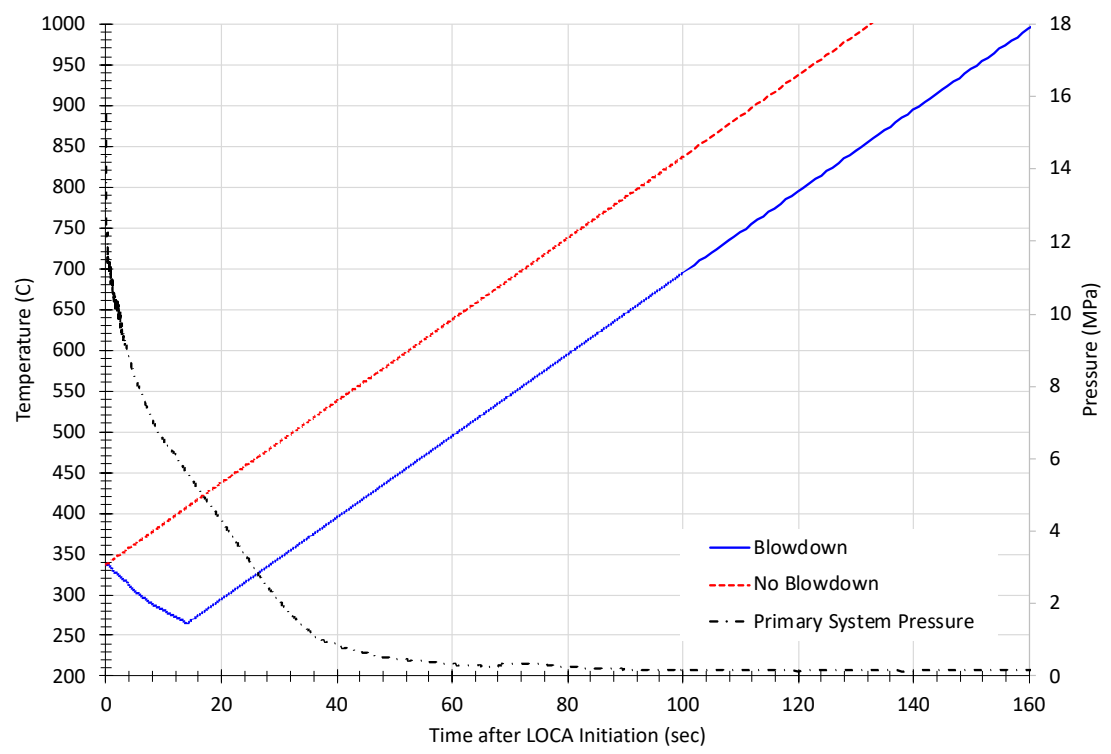

Fig. 11. PCT for the blowdown vs. no blowdown thermal boundary condition. 
Table 2. Full-length fuel rod heating rates and pre-transient pressure conditions

\begin{tabular}{|c|c|c|c|c|}
\hline \multirow[t]{2}{*}{ LOCA heating rates $\left({ }^{\circ} \mathrm{C} / \mathrm{s}\right)$} & \multicolumn{4}{|c|}{$\begin{array}{c}\text { Pre-transient rod internal pressures at } 330^{\circ} \mathrm{C}(\mathrm{MPa}) / \\
\text { Pressure differential [RIP-System] }(\mathrm{MPa})\end{array}$} \\
\hline & $11.3 /-4.2$ & $12.3 /-3.2$ & $14.6 /-0.9$ & $22.8 /+7.3$ \\
\hline 5 & $\mathrm{X}$ & $\mathrm{X}$ & $\mathrm{X}$ & $\mathrm{X}$ \\
\hline 10 & $\mathrm{X}$ & $\mathrm{X}$ & $\bar{X}$ & $\bar{X}$ \\
\hline 15 & $\mathrm{X}$ & $\mathrm{X}$ & $\mathrm{X}$ & $\bar{X}$ \\
\hline 20 & $\mathrm{X}$ & $\mathrm{X}$ & $\mathrm{X}$ & $\mathrm{X}$ \\
\hline
\end{tabular}

Finally, two cladding burst criteria were considered in this evaluation. The first is a stress-based failure criterion used by the US Nuclear Regulatory Commission (NRC) in the FRAPTRAN code [50]. The second is a strain rate-based criterion [48]. Temperatures during a simulated LOCA event are such that Zircaloy rapidly deforms when a rod internal pressure is applied. As temperature increases, the rate of deformation increases until the material is no longer capable of maintaining structural stability, at which time burst occurs. This burst mechanism is attributed to plastic instability and is defined by Eq. (1):

$$
\dot{\epsilon} \geq \sim 0.0278 s^{-1} \text {. }
$$

\subsection{Commercial Fuel Rod Analysis Results}

BISON was used to evaluate cladding performance when considering a blowdown and the possibility of cladding heating at the onset of the LOCA (i.e., no-blowdown, and conditions similar to those during an infrared furnace burst test). The intent of the analysis was twofold. First, it is necessary to understand whether there are differences between the results. Conceptually, the results are expected to be similar; however, confirmation is required. Secondly, it is important to have a baseline analysis of the fuel rod evolution during LOCAs for both scenarios. Essentially, the time evolution for key fuel performance parameters must be considered, along with the impact of this evolution on fuel performance. The results for the two analyses are shown in Fig. 12. Rod internal pressure (Fig. 12a) and temperature (Fig. 12b) perform as expected. The blowdown results in the temperature and pressure dropping at constant rates until a quasi-equilibrium is reacted $(\sim 20-35 \mathrm{~s})$. This observation is explained by the ideal gas law. As the fuel rod begins to heat, the plenum temperature increases; however, the rod's internal pressure continues to decrease rather slowly. This is the result of elastic and plastic (i.e., creep) deformation occurring faster than the temperature increase. When the blowdown phase is removed, the plenum temperature begins heating immediately, but the rod's internal pressure decreases slightly. This decrease is related to the delta pressure change across the cladding as the system pressure is removed. Removing the system pressure $(\sim 15.5 \mathrm{MPa})$ is enough to cause cladding liftoff and creep, thereby increasing the void volume and decreasing the pressure. Cladding stress and strain are very consistent between the two cases except in the no-blowdown case, because it reaches elevated temperatures faster, and ballooning occurs sooner (Fig. $12 \mathrm{c}$ and $2 \mathrm{~d})$. 


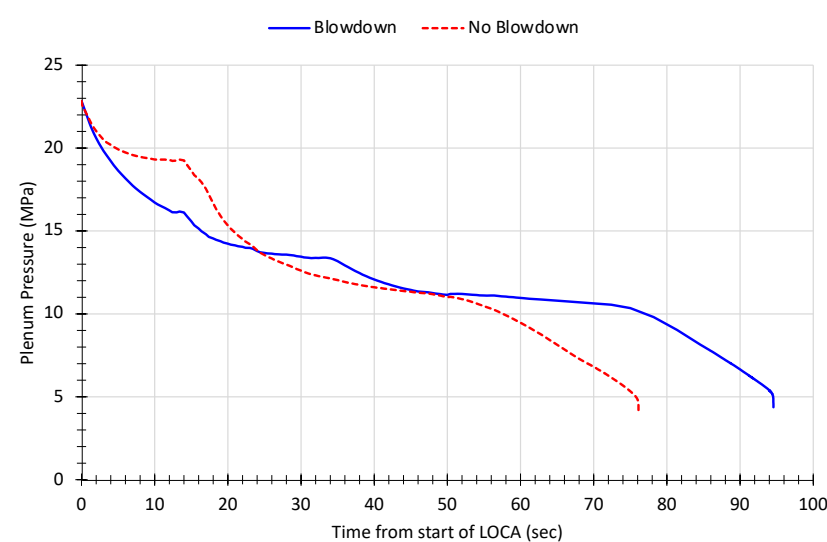

(a)

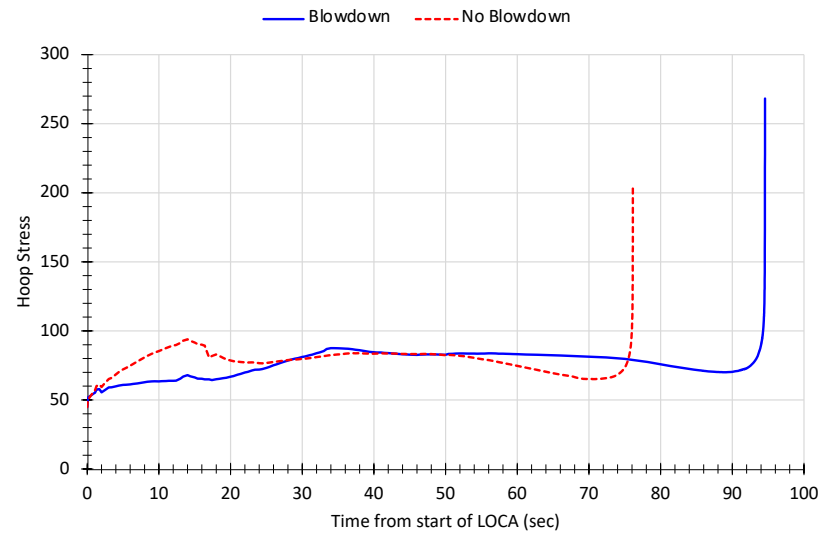

(c)

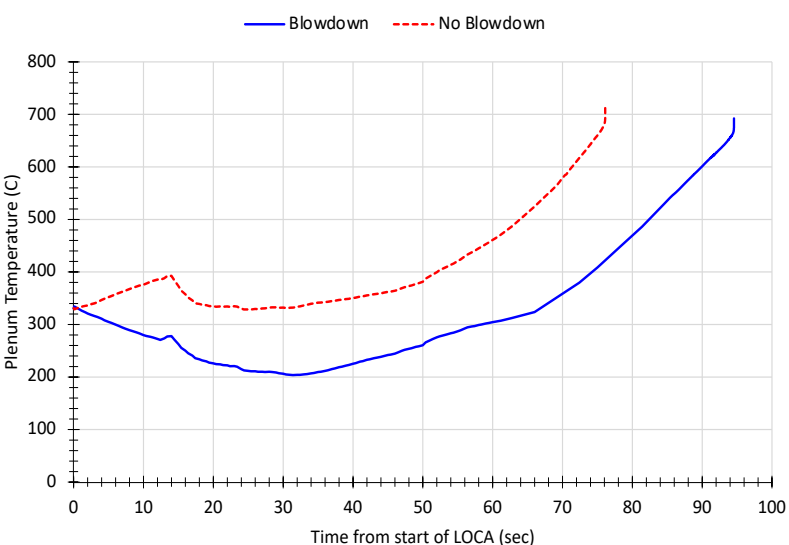

(b)

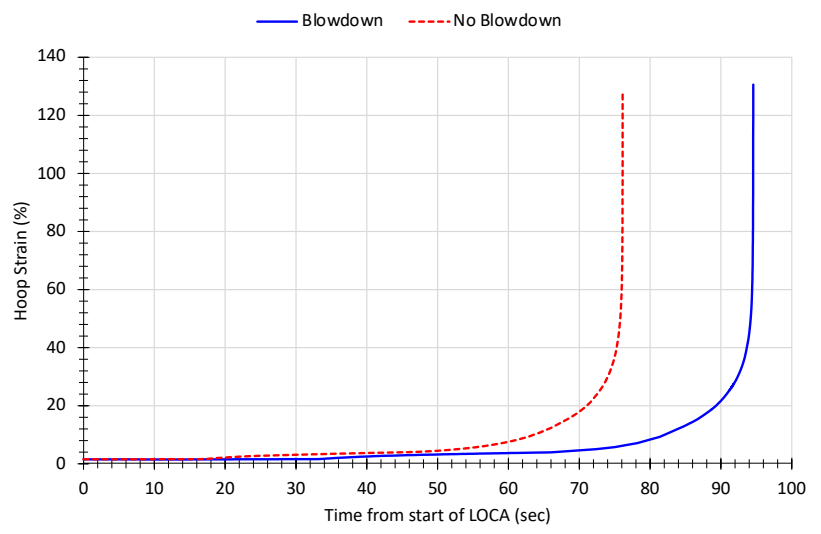

(d)

Fig. 12. Analysis assessing the impact of blowdown vs. an event where blowdown is not considered.

Table 3 summarizes the burst conditions predicted by the stress and strain rate-based burst criteria. The burst temperature, stress, and peak strain are generally consistent between the two simulations. There is a $\sim 35^{\circ} \mathrm{C}$ difference in the burst temperature between the stress-based $\left(\sim 747-756^{\circ} \mathrm{C}\right)$ and strain rate-based $\left(\sim 780-795^{\circ} \mathrm{C}\right)$ failure models. The stress-based failure model provides a more conservative (i.e., lower) burst temperature, whereas the strain rate-based failure model provides a higher burst temperature and a more conservative (i.e., bigger) balloon size. The two results are significant when considering the possible implications on FFRD. For example, bursting at higher temperatures might reduce or possibly mitigate pulverization; however, larger balloon strains - and likely larger burst openings - suggest that the fuel will have a higher propensity to relocate into the ballooned region and to ultimately disperse. Bursting at lower temperatures likely increases pulverization susceptibility, but the balloon strain is smaller and likely has a smaller burst opening. Therefore, the fuel will be less likely to relocate and disperse. Both failure models suggest that the cladding will burst at higher temperatures than those observed experimentally. High-burnup and high-pressure (pre-pressurized to $\sim 11 \mathrm{MPa}$ at $300-330^{\circ} \mathrm{C}$ ) integral LOCA tests performed at Studsvik indicated that burst occurs between 680 and $700^{\circ} \mathrm{C}[52,53]$. However, BISON suggests that a full-length fuel rod with a pre-transient rod internal pressure of $22.3 \mathrm{MPa}$ at $\sim 330^{\circ} \mathrm{C}$ will not burst until a minimum cladding temperature of $\sim 750^{\circ} \mathrm{C}$ is reached. This discrepancy between the rodlet burst test and the full-length cladding performance is evaluated in more detail below. 
Table 3. Comparison of burst conditions comparison for blowdown and no-blowdown events

\begin{tabular}{|c|c|c|c|c|c|c|}
\hline \multirow{2}{*}{} & \multicolumn{3}{|c|}{ Stress-based burst criteria } & \multicolumn{3}{c|}{ Strain rate-based burst criteria } \\
\cline { 2 - 7 } & $\begin{array}{c}\text { Burst } \\
\text { temperature } \\
\text { I }\left({ }^{\circ} \mathrm{C}\right)\end{array}$ & $\begin{array}{c}\text { Burst } \\
\text { stress } \\
(\mathrm{MPa})\end{array}$ & $\begin{array}{c}\text { Peak } \\
\text { hoop } \\
\text { strain at } \\
\text { burst }(\%)\end{array}$ & $\begin{array}{c}\text { Burst } \\
\text { temperature I } \\
\left({ }^{\circ} \mathrm{C}\right)\end{array}$ & $\begin{array}{c}\text { Burst } \\
\text { stress } \\
(\mathrm{MPa})\end{array}$ & $\begin{array}{c}\text { Peak hoop strain at } \\
\text { burst }(\%)\end{array}$ \\
\hline Blowdown & 747 & 70 & 15.2 & 780 & 72 & 27.2 \\
\hline No blowdown & 756 & 65 & 16.5 & 795 & 67 & 26.3 \\
\hline
\end{tabular}

The previous analysis showed minimal differences between LOCA scenarios that do and do not consider the blowdown phase, provided that the heating rates are identical. This affords an opportunity for a more detailed high-burnup LOCA fuel performance analysis. There are two primary parameters governing cladding performance during the refill phase of a LOCA: (1) pre-transient rod internal pressure and (2) heating rates. Some argue that irradiation-induced embrittlement, hydrogen embrittlement, and oxidation might impact cladding LOCA performance, but there are not enough data to observe any meaningful difference. Furthermore, elevated temperatures will anneal irradiation damage and dissolve hydride precipitates back into solution, thereby countering any potential material degradation. Hydrogen is very important for post-quench ductility; however, this topic is outside the scope of this manuscript. Large oxides could impact cladding performance, but advanced Zircaloy claddings have shown a drastic reduction in oxide thickness when compared with Zry-4. Nonetheless, this will be a topic for future consideration.

Fig. 13 shows an assessment of the impact of heating rate and rod internal pressure on cladding burst temperature (Fig. 13a) and hoop strain (Fig. 13b) using the conservative stress-based burst criteria. Fig. 13a indicates that the burst temperature increases as the pre-transient pressure decreases and heating rates increase. Again, burst temperatures are noticeably high $\left(>800^{\circ} \mathrm{C}\right)$ for such high initial rod internal pressures. Hoop strain results shown in Fig. $13 \mathrm{~b}$ are consistent, except for the $22.8 \mathrm{MPa}$ simulations. One reason for this discrepancy could be that the high-temperature creep model might be inappropriate for such high rod internal pressure; therefore, balloon strains might be underpredicted. However, increasing the creep rate might increase burst temperatures because the cladding will be more adept at reducing stress. The strain rate-based burst criteria were also considered, and compared with the stress-based failure criteria, the strain rate failure criteria increased cladding burst temperatures by $40^{\circ} \mathrm{C}$ on average, and they also increased hoop strains. Both failure criteria show burst occurring at high temperatures; however, the additional burst margin afforded by the strain rate failure criteria could be enough margin to mitigate burst in high-burnup fuel. Additional thermal hydraulic and fuel performance studies that consider possible uncertainties are needed to confirm.

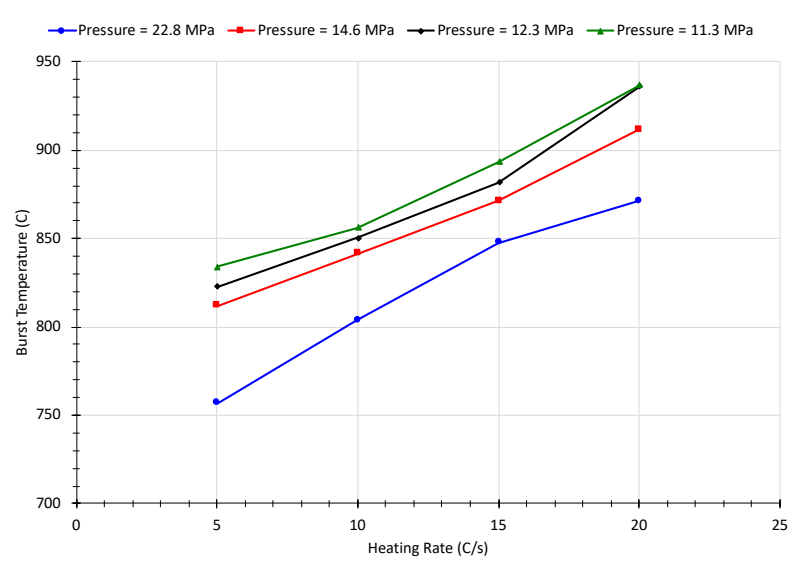

(a)

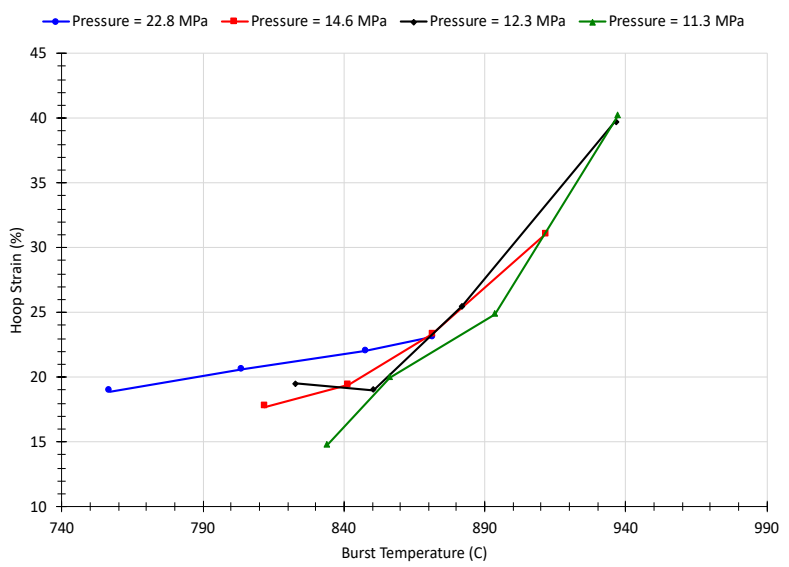

(b) 
Fig. 13. Evaluating the impact of (a) burst temperature as a function of heating rate and constant pre-transient rod internal pressure and (b) burst strain as a function of burst temperature and pretransient rod internal pressure using the more conservative stress-based burst conditions.

One common difference continues to arise between rodlet burst test and full-length fuel rod burst analyses. The difference is associated with the full-length fuel rod burst temperatures predicted by BISON, which indicate that burst occurs at high cladding temperatures, even with excessively high pretransient rod internal pressures. What is unclear is why rodlet burst test results differ from full-length fuel rod analysis results. A simple explanation could be that experimental rodlets are $\sim 12 \times$ shorter than fulllength fuel rods. There are a limited number of LOCA experiments on full-length fuel rods [55, 54], and to date, BISON has been validated against the National Research Universal (NRU) reactor Material Test (MT). BISON validation to some of these fuel rods can be reviewed in Williamson et al. [47]. These tests are important because the pre-test rod internal pressure is $\sim 9-9.5 \mathrm{MPa}$ at $\sim 330^{\circ} \mathrm{C}$, which is reasonably close to the results presented above. The burst conditions were reported to occur at $\sim 805-840^{\circ} \mathrm{C}$, and BISON generally predicted the burst temperature accurately for both rods.

The REBEKA test series also included a simulated LOCA on assemblies that contain full-length fuel rods, and the cladding conditions were well characterized for these tests. The optimum case is the REBEKA 2 case, in which the fuel rod was heated in a steam environment with burst occurring during the heating phase. Other REBEKA tests have complicated heat transfer conditions, making the analysis very difficult and full of uncertainties in the absence of detailed thermal hydraulic analysis results. REBEKA 2 consisted of a $7 \times 7$ fuel assembly with nine grid spacers equally spaced across the axial length. Details related to the fuel rod geometries and system conditions are shown in Table 4. One important distinction from other burst tests is that these fuel rods were pressurized at $520^{\circ} \mathrm{C}$, whereas many tests pressurize the rods at room temperature or hot-zero-power conditions $\left(\sim 320^{\circ} \mathrm{C}\right)$. Each fuel rod within the assembly contained heating elements that spanned the full length of the tube. A cosine power profile was applied to every fuel rod, and the peak power location was axially located in the center of the fuel rods. The intent was to maximize the local ballooning of each tube to assess the impact of flow blockage on cooling. Fig. 14 illustrates the power profile as reproduced from Capps et al. [25]. Cladding temperature measurements were also taken near the burst location, providing BISON with an accurate thermal boundary for performing the validation effort. The measured temperature is shown in Fig. 15. 
Table 4. REBEKA 2 fuel rod geometry and test conditions $[56,55]$

\begin{tabular}{|l|c|c|}
\hline \multicolumn{1}{|c|}{ Test condition } & Value & Units \\
\hline System pressure & 0.101 & $\mathrm{MPa}$ \\
\hline Heating rate & 7 & ${ }^{\circ} \mathrm{C} / \mathrm{s}$ \\
\hline Rod internal pressure $\left(\right.$ at $\left.520^{\circ} \mathrm{C}\right)$ & 7 & $\mathrm{MPa}$ \\
\hline Cladding outer diameter & 10.75 & $\mathrm{~mm}$ \\
\hline Cladding inner diameter & 9.3 & $\mathrm{~mm}$ \\
\hline Cladding thickness & 0.725 & $\mathrm{~mm}$ \\
\hline Segment length & 3,900 & $\mathrm{~mm}$ \\
\hline Cladding type & \multicolumn{2}{|c|}{ Zry-4 } \\
\hline
\end{tabular}

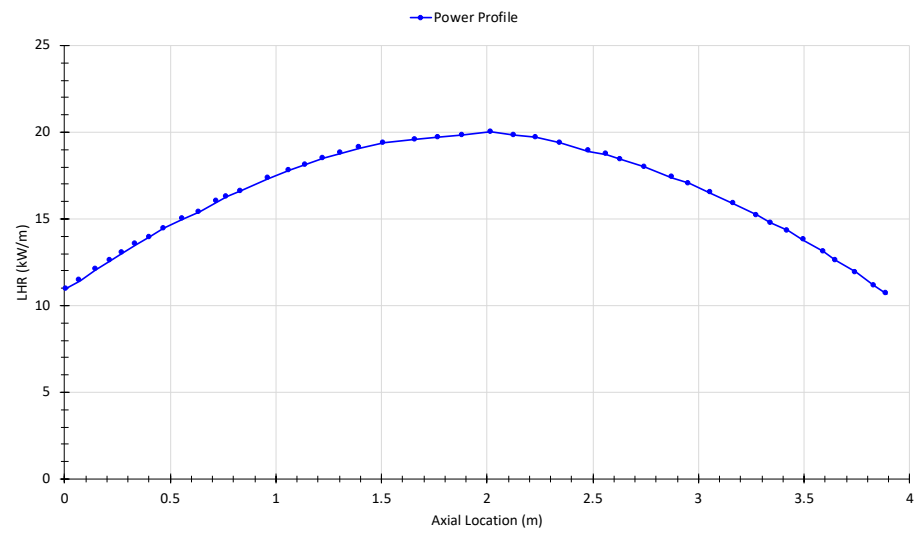

Fig. 14. REBEKA 2 axial power profile $[56,55]$.

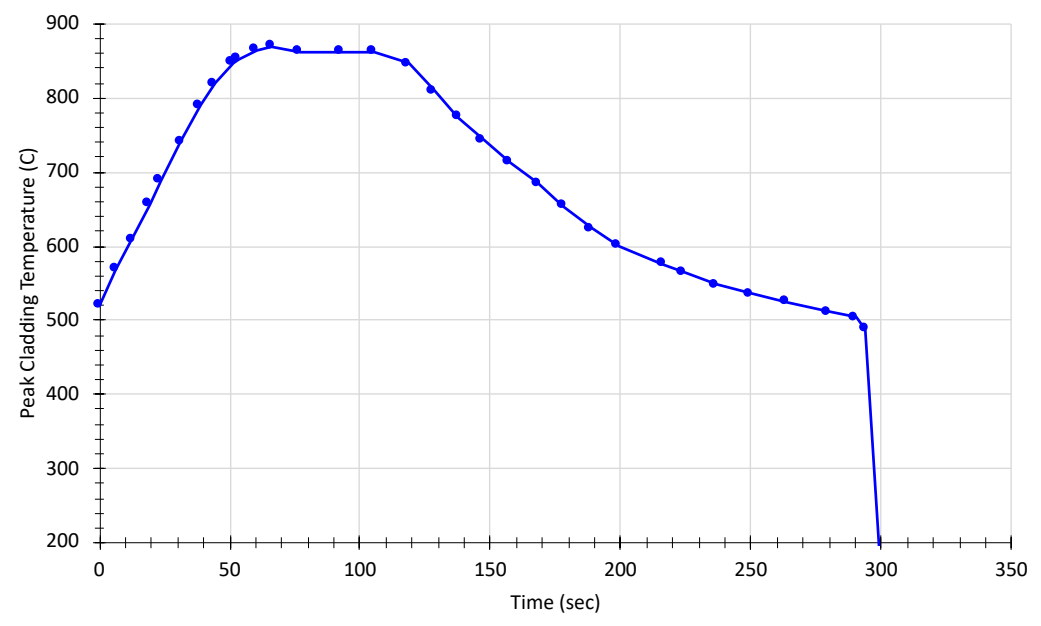

Fig. 15. REBEKA 2 temperature at the burst location $[56,55]$.

The BISON assessment of the REBEKA 2 fuel bundle LOCA test is shown in Table 5. The stress-based burst criteria underpredicts all experimentally measured conditions. Measured cladding hoop strains ranged from $\sim 20-60 \%$ within the fuel assembly, with the average shown in Table 5. BISON hoop-strain predictions under-predict even the smallest hoop strain value. However, the strain-rate burst criterion predicts near-accurate results, except for hoop strain. The burst temperature was conservative by $2^{\circ} \mathrm{C}$, and the burst pressure was slightly lower than measured. Hoop strain results were still lower than the smallest reported strain value. Excluding hoop strain, BISON burst temperature predictions are conservative, even for a full-length fuel rod. Burst pressure results are considered reasonable, and differences could be the 
result of subtle differences in the assumed void volume (e.g., plenum length and pellet-cladding gap). Improvements to hoop strain predictions require in situ 3D stain and stain-rate data to quantify why BISON underpredicts hoop strain. Additionally, there could be azimuthal temperature effects not considered in the analysis that could impact local strain results and are not appropriately reflected in the BISON analysis. However, these subtle changes would not impact the instantaneous rod internal pressure but could impact the burst temperature.

Table 5. BISON comparison to REBEKA 2 experimental result $[56,55]$

\begin{tabular}{|c|c|c|c|c|}
\hline & Experiment & $\begin{array}{c}\text { Stress-based burst } \\
\text { criteria }\end{array}$ & $\begin{array}{c}\text { Creep rate burst } \\
\text { criteria }\end{array}$ & Units \\
\hline $\begin{array}{c}\text { Burst } \\
\text { temperature }\end{array}$ & 870 & 829 & 868 & ${ }^{\circ} \mathrm{C}$ \\
\hline Burst pressure & 5.5 & 5.8 & 5.2 & $\mathrm{MPa}$ \\
\hline $\begin{array}{c}\text { Average hoop } \\
\text { strain }\end{array}$ & 54 & 6.1 & 12.5 & $\%$ \\
\hline
\end{tabular}

BISON validation against the REBEKA 2 test, as well as results reported in Williamson et al. [47], suggests that the full-length fuel rod analyses are reasonable; however, the validation results do not indicate any of the high-burst conditions observed in the previous BISON commercial fuel-rod simulations. One consideration might be the peaking factor. The REBEKA and NRU tests had a very pronounced cosine shape, which was intended to maximize the balloon characteristics in a local region. However, peaking factors calculated by RELAP5 suggest that the axial cladding temperature is flatter than those used in the experiments. This observation is shown in Fig. 16, which compares the timedependent maximum-peaking factor calculated by RELAP for a high-burnup fuel rod with the REBEKA test maximum-peaking factor. The RELAP-calculated peaking factor remains well below the REBEKA peaking factor for most of the simulation. Eventually, RELAP calculates a higher peaking factor than the REBEKA test because the quench front pushes the peaking factor toward the upper regions of the fuel rod. Therefore, it is conceivable that the higher burst conditions could be related to the lower peaking factors observed during a "realistic" LOCA.

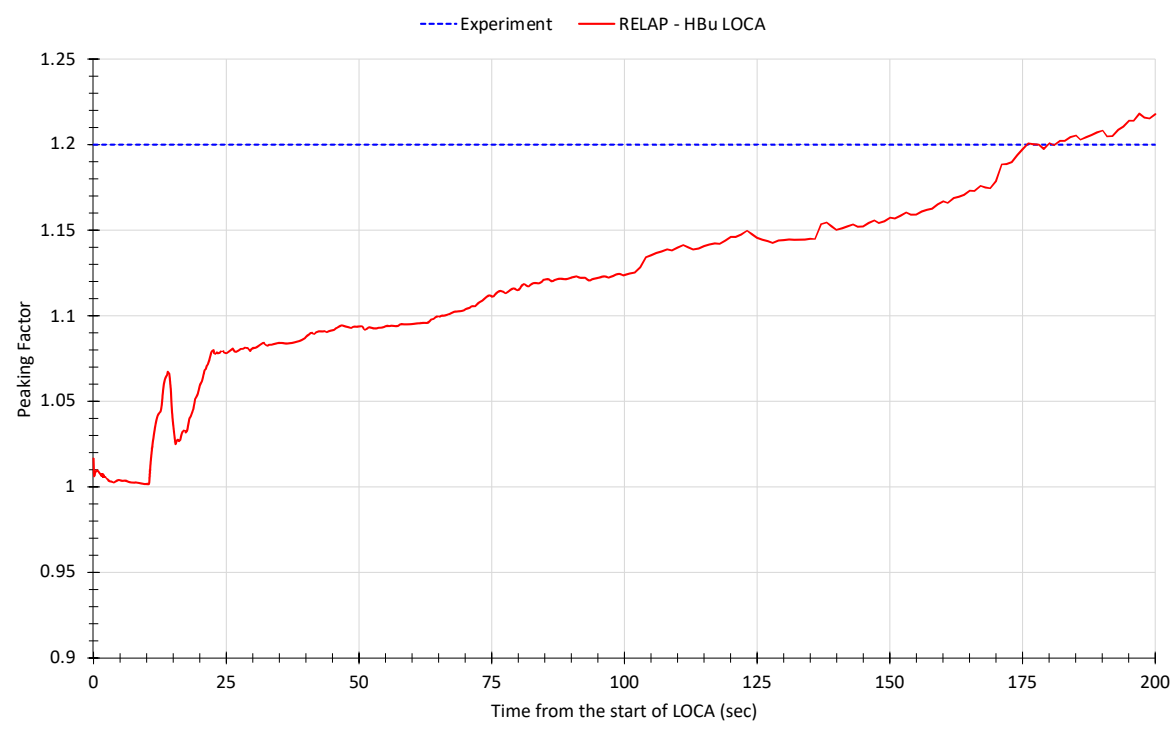

Fig. 16. REBEKA 2 Experimental peaking factor compared with peaking factors calculated by RELAP5-3D for a high-burnup commercial fuel rod [56, 25]. 
To test this theory, a cladding temperature profile was taken during the LOCA heating phase and applied to the same REBEKA analysis. A comparison between the REBEKA and RELAP axial profiles is shown in Fig. 17. The two axial profiles clearly indicate that the RELAP profile will ensure that the cladding temperature remains flatter over the span of the fuel rod compared with the REBEKA profile. Table 6 summarizes the BISON results between the two simulations. The stress-based and strain-rate failure criteria suggest that the cladding burst temperature increases by $10-15^{\circ} \mathrm{C}$, whereas the hoop strain decreases. The change in burst conditions is attributed to the larger void volume generated by the flatter temperature profile, which induces additional axial ballooning. However, the observed difference is minimal when considering that the calculated burst conditions are significantly higher than those observed in the rodlet test.

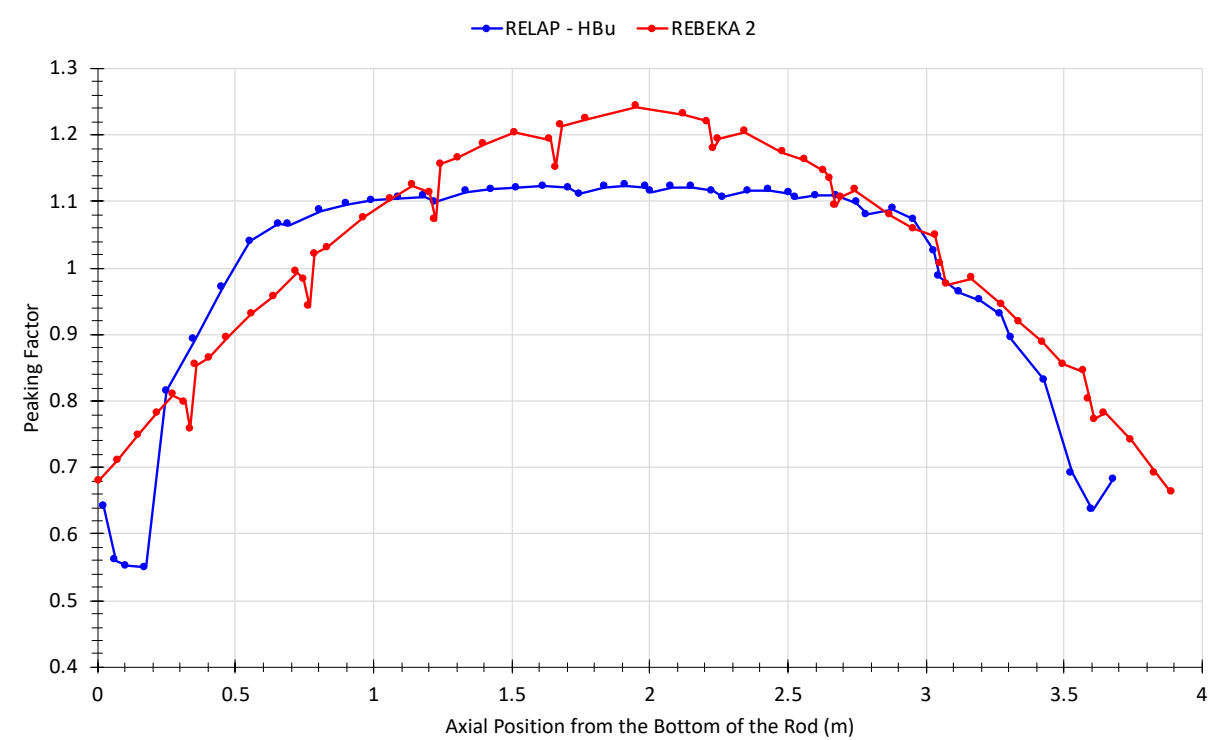

Fig. 17. Comparison between REBEKA 2 and RELAP HBu LOCA axial temperature profiles $[56,25]$.

Table 6. BISON results evaluating the impact of axial cladding temperature profile on cladding burst conditions $[56,55]$.

\begin{tabular}{|c|c|c|c|c|c|c|}
\hline & & \multicolumn{2}{|c|}{ REBEKA 2 profile } & \multicolumn{2}{c|}{ RELAP HBu LOCA profile } & \\
\cline { 2 - 7 } & Experiment & $\begin{array}{c}\text { Stress-based } \\
\text { burst criteria }\end{array}$ & $\begin{array}{c}\text { Creep rate } \\
\text { burst criteria }\end{array}$ & $\begin{array}{c}\text { Stress- } \\
\text { based } \\
\text { burst } \\
\text { criteria }\end{array}$ & $\begin{array}{c}\text { Creep rate } \\
\text { burst criteria }\end{array}$ & Units \\
\hline $\begin{array}{c}\text { Burst } \\
\text { temperature }\end{array}$ & 870 & 829 & 868 & 844 & 878 & ${ }^{\circ} \mathrm{C}$ \\
\hline $\begin{array}{c}\text { Burst } \\
\text { pressure }\end{array}$ & 5.5 & 5.8 & 5.2 & 5.3 & 4.6 & $\mathrm{MPa}$ \\
\hline $\begin{array}{c}\text { Average hoop } \\
\text { strain }\end{array}$ & 54 & 6.1 & 12.5 & 5.1 & 9.5 & $\%$ \\
\hline
\end{tabular}

One additional scenario not considered in the experiments or axial profile comparison is possible in a commercial reactor LOCA. As indicated in Fig. 17, calculated full-core LOCA cladding temperatures are flatter than those traditionally observed in an experiment. However, the cladding temperature profile evolves as a function time (Fig. 18). Early in the refill phase, the cladding temperature profile is effectively flat for both the high-burnup (Fig. 18a) and low-burnup hot rod (Fig. 18b) fuel rod. As the 
quench front progresses, the peaking factor near the bottom of the rod decreases, whereas the peaking factor in the upper region increases. This is consistent with the quench front cooling the bottom regions of the fuel rod while the upper regions remain in a quasi-adiabatic state. Ultimately, this means the instantaneous PCT initially starts at a lower axial location, and as the quench front progresses, the instantaneous PCT progresses upward. This occurrence is shown clearly in Fig. 18b, and the data in Table 7 show that the instantaneous PCT moves $\sim 1 \mathrm{~m}$ in the axial direction. Therefore, the cladding at that instant begins ballooning, increasing the void volume and ultimately decreasing the rod internal pressure. However, $\sim 25-50$ s later, the instantaneous PCT shifts to a new axial location and starts the ballooning process in the new location higher on the fuel rod. This continues until the PCT comes to rest at a terminal axial location. This process creates a transient ballooning front that results in the initiation of multiple balloons, thereby increasing the void volume and decreasing rod's internal pressure so that higher temperatures are required to burst the cladding.

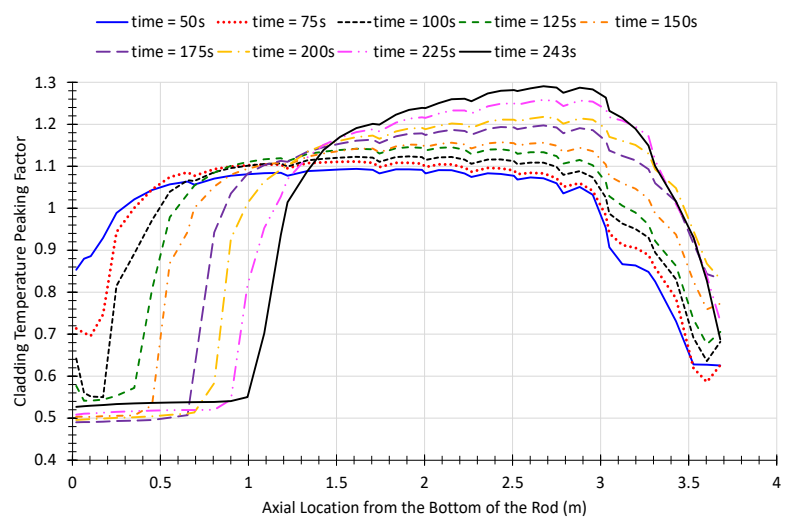

(a)

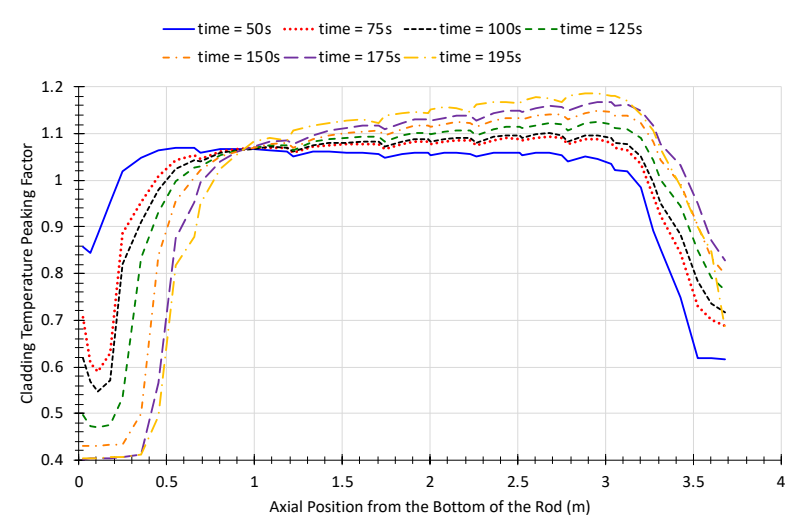

(b)

Fig. 18. Cladding temperature peaking factors as a function of time for (a) high burnup ( $\sim 72 \mathrm{GWd} / \mathrm{tU}$ rod average) and (b) low burnup ( $\sim 40 \mathrm{GWd} / \mathrm{tU}$ rod average) [25].

Table 7. Peak peaking factor for each time and associated location

\begin{tabular}{|c|c|c|c|c|}
\hline \multirow{2}{*}{ Time (s) } & \multicolumn{2}{|c|}{ Low burnup } & \multicolumn{2}{|c|}{ High burnup } \\
\hline & Location (m) & Peaking factor & Location (m) & Peaking factor \\
\hline 50 & 0.553 & 1.070 & 1.613 & 1.092 \\
\hline 75 & $\begin{array}{l}2.675 \\
2.955\end{array}$ & $\begin{array}{l}1.093 \\
1.089\end{array}$ & 1.613 & 1.111 \\
\hline 100 & $\begin{array}{l}2.675 \\
2.955\end{array}$ & $\begin{array}{l}1.100 \\
1.096\end{array}$ & 1.911 & 1.123 \\
\hline 125 & $\begin{array}{l}2.675 \\
2.955\end{array}$ & $\begin{array}{l}1.122 \\
1.124\end{array}$ & 2.153 & 1.145 \\
\hline 150 & $\begin{array}{l}2.675 \\
2.955\end{array}$ & $\begin{array}{l}1.143 \\
1.148\end{array}$ & 2.433 & 1.157 \\
\hline 175 & $\begin{array}{l}2.675 \\
2.955\end{array}$ & $\begin{array}{l}1.159 \\
1.168\end{array}$ & 2.675 & 1.197 \\
\hline 195 & $\begin{array}{l}2.601 \\
2.881\end{array}$ & $\begin{array}{l}1.177 \\
1.187\end{array}$ & N/A & N/A \\
\hline 200 & N/A & $\mathrm{N} / \mathrm{A}$ & 2.675 & 1.217 \\
\hline 225 & N/A & N/A & 2.675 & 1.258 \\
\hline 243 & N/A & N/A & 2.675 & 1.290 \\
\hline
\end{tabular}

The occurrence depicted in Fig. 18b is more complex because the cladding temperature profile remains relatively flat for the duration of the LOCA transient. This indicates a hot rod scenario. Like the highburnup rod, the quench front decreases the cladding peaking factors near the bottom; however, the peak 
peaking factors span across a longer region of the fuel (Table 7). The peak peaking factors shown in Table 7 indicate that the instantaneous PCT occurs in two axial locations separated by a grid spacer or mixing vein. This specific condition allows the cladding to balloon in two different but adjacent axial locations as the grid spacer locally suppresses ballooning mechanically and thermally. The end result is somewhat similar to the high-burnup fuel rod in which the double balloon event increases the void volume and decreases the rod's internal pressure. Eventually, a subtle change in the temperature conditions results in the continuation of the ballooning process for one of the balloons, whereas the other balloon comes to rest, but not before the burst conditions increase to a point much higher than those observed experimentally.

\subsection{Cladding Burst Tube Evaluation and Experimental Development}

To demonstrate the difference between the cladding burst model prediction from a cladding rodlet burst test and a full-length fuel rod under LOCA conditions, a burst test simulation was developed for each situation to compare the cladding behavior. During the cladding burst experiment, the cladding was heated in a furnace by using infrared heaters, and internal pressure was controlled through a pressurized tank with a pressure regulator. The cladding tube temperature was increased to a representative steadystate temperature, the gas was adjusted, and then the gas valve was closed. Then, the cladding temperature was increased until failure.

This test has several challenges when extrapolating to full-length fuel rods. Specifically, the void volume must correspond to the scaled length of the cladding tube specimen, and the temperature gradients must be representative of those experienced in the LWR during the transient. These are important for gas pressure evolution, which is the driving force in the ballooning behavior. With a smaller gas void volume, the internal pressure will decrease more for a given cladding deformation. This allows the cladding balloon to relieve the internal pressure, and it may artificially increase the temperature that the cladding can withstand. Although sharp temperature gradients, which also directly influence the thermal creep deformation, might not experience the expected increase in gas pressure for a given maximum temperature, this creates a local hot spot in which the cladding is likely to fail, thereby quickly generating smaller balloon lengths.

Burst tests were conducted on Ziraloy-4 cladding tubes via ORNL's Severe Accident Test Station (SATS) system [27]. After the initial equipment alignment, one of the tests performed was selected for benchmarking because of the accurate machine calibration and reliability issues with thermocouples in subsequent tests. To approximate the proportion of gas volume in the cladding tube more closely, zirconia pellets were seated in the cladding tube. This test included three stages: (1) the temperature was stabilized during the initial heating, (2) the tube was pressurized and sealed, and (3) the temperature was ramped until the cladding ruptured.

To benchmark BISON against these data, a simulation of this burst test was performed. To construct this simulation, a 2D-RZ representation of this geometry was used, along with thermocouple and pressure measurements from the original test, although these data were slightly altered. The thermocouple measurements were used to generate a continuous temperature surface across the cladding to ensure that areas far from the thermocouples still had temperatures prescribed to them. Thermocouples from the original experiment were placed at the cladding midplane and at $\pm 5.08 \mathrm{~cm}$ from that location. The boundary conditions used here applied to the entire rod length. After the initial gas charge into the cladding tube, the internal pressure was calculated by using the cladding temperature profile and the internal volume similar to that observed in an LWR. This model was modified to account for the additional gas trapped in the line from the gas valve to the cladding, which represents a significant proportion of the gas volume at a lower temperature. The cladding material models used in this analysis are described in a previous analysis [25].

During this simulation, the cladding ruptured at a peak measured temperature of $837^{\circ} \mathrm{C}$ and an engineering hoop stress of 51.6 MPa. Table 8 compares the BISON results with the data from the burst 
experiment. In the simulation, the cladding bursts at a lower thermocouple temperature and engineering hoop stress. Practically, this is likely the result of an effect of azimuthal temperature variation, which is not captured in the experiment or modeled in this simulation. The variation of the cladding temperature around the cladding circumference is caused by the nonuniform heating conditions in the experiment and leads to hot spots that are likely to cause premature cladding failure [27,55]. Additionally, because the experiment only measures temperature at three locations along a relatively short span of the cladding, the temperature at the cladding ends is not characterized. This leads to uncertainty in the temperature profile when developing the boundary conditions for the simulation. Lastly, the specific cladding thermal creep model also greatly influences how quickly the cladding will reach failure, and uncertainties here will impact nearly all aspects of the cladding behavior during the ballooning phase.

Table 8. Summary of the cladding burst conditions for the experiment and BISON simulation

\begin{tabular}{|c|c|c|c|}
\hline Data & $\begin{array}{c}\text { Peak thermocouple } \\
\text { temperature }\left({ }^{\circ} \mathbf{C}\right)\end{array}$ & $\begin{array}{c}\text { Peak engineering } \\
\text { hoop stress (MPa) }\end{array}$ & $\begin{array}{c}\text { Peak engineering hoop strain } \\
(\mathbf{\%})\end{array}$ \\
\hline Zry4-21 & 837 & 51.54 & 37 \\
\hline BISON & 788 & 49.02 & 12.7 \\
\hline
\end{tabular}

To simulate the LWR LOCA conditions, a nearly flat temperature profile is applied to the previous rodlet test simulation. This corresponds to the conditions from the full-length analysis discussed previously. All other aspects of the simulation are identical; the only change is the temperature gradient. Figure 9 shows the temperature gradients used for these two simulations. Notably, the conditions from the actual burst experiment show a monotonically increasing temperature along the axial length of the cladding, and the expected LWR conditions show a gradual cosine shape. Two categories of criteria are traditionally used for cladding failure: stress based and strain based. As mentioned in Section 3.1 above, the stress-based criteria typically underpredict the cladding stress and temperature at failure by a fair margin, whereas strain-based — in this case, strain rate_criteria report more accurate results.

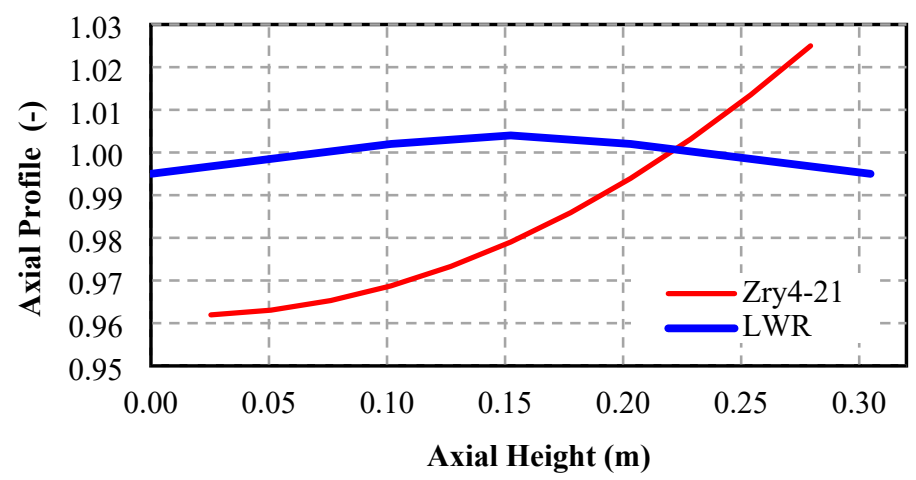

Fig. 19. Axial temperature profiles from Zry4-21 (red) and for the LWR (blue) simulation.

Fig. 20 shows the cladding stress vs. the maximum cladding temperature for both the cladding burst experiment (Zry4-21) and the corresponding simulation by using the LWR-like temperature gradient. The black dashed line is the stress-based failure criteria for a heating rate of $4{ }^{\circ} \mathrm{C} / \mathrm{s}$. This figure demonstrates that both cladding simulations burst at higher temperatures and stresses than predicted with the burst model, and the LWR simulation reaches an even higher temperature $\left(\sim 30^{\circ} \mathrm{C}\right.$ higher $)$. 


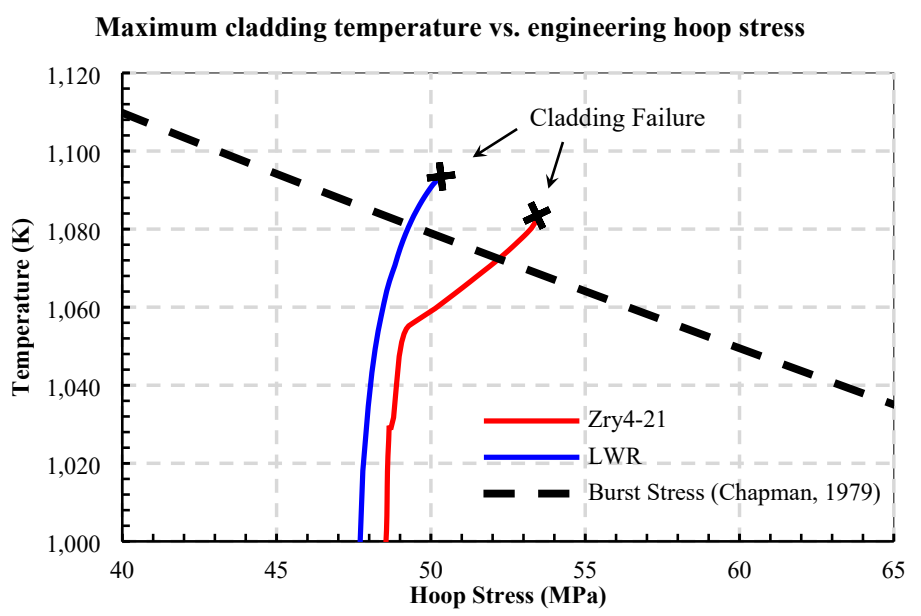

Fig. 20. Cladding rupture temperature and stress for rodlet using measured experiment conditions (red) and LWR-like temperature gradient (blue).

These simulations show that for the more gradual temperature gradient, the cladding deformation is more distributed along the cladding length, which slightly delays rupture relative to the sharp gradient from the burst test. This means that additional consideration might be necessary when applying a failure model generated in this manner to full-length LWR conditions. Essentially, local variations in the cladding temperature experienced during the experiment can generate models with reduced temperature thresholds. These same temperature variations are not expected for fuel rods under LOCA conditions in an LWR.

The ideal burst test will have a more thorough characterization of the cladding temperature, internal void volume, LWR fuel-to-volume ratios, and cladding strain. Although sharp axial and radial temperature gradients can lead to early cladding failure, they are not inherently deleterious effects if the conditions are well characterized. To account for this, additional temperature instrumentation would help better define the cladding temperature surface and capture some of these effects, which can then be modeled. The cladding's internal gas volume, including the volume trapped in the test rig gas lines, also needs better characterization. The cladding ballooning process should decrease the internal pressure as it progresses, and as such, the simulation needs an accurate measurement of the total gas volume and temperature to account for pressure drop as the cladding deforms. Finally, the full characterization of the cladding tube strain would allow these simulations to be compared using fully 3D models.

\subsection{Summary}

This paper highlights differences between the expected behavior of commercial fuel rods and cladding experiments under conditions in which cladding burst rupture is expected to occur. Evaluations of commercial fuel rod LOCA burst conducted with BISON suggest that commercial fuel rods will burst at higher temperatures than those observed in simulated LOCA tests. There are several possible reasons for this observed behavior. First, commercial fuel rods are significantly longer $(\sim 3.6-3.9 \mathrm{~m})$ than rodlets used in a simulated LOCA test $(0.3 \mathrm{~m})$, and because commercial fuel rods have a smaller fuel-to-volume ratio and a changing temperature profile, the rod's internal pressure decreases at a faster rate as the cladding deforms. This sustained pressure allows ballooning to occur axially along the cladding, with the increased deformation corresponding to higher temperatures. Fuel rod temperatures uniformly increase until the reflood process begins quenching the fuel rod from bottom to top. As the reflood process progresses, local axial regions of the fuel rod cool, thereby terminating the local ballooning process. This results in subsequently smaller changes to the fuel rod's internal volume and pressure conditions. Consequently, 
upper spans of the cladding tube are subject to increased temperatures for a longer period, allowing larger balloon sizes to form, and increasing the likelihood of burst.

However, the results of the representative full-length fuel rod LOCA simulations do not agree with the cladding balloon tests. Cladding burst tests indicated that burst should occur at lower temperatures $\left(<800^{\circ} \mathrm{C}\right)$ for similar and even much lower pressures. Further analysis showed that cladding burst tests were not representative of full-length fuel rod tests and needed to be improved to better represent realistic conditions. Furthermore, there is a significant lack of information to adequately model these experiments. The disagreement observed in this work showed differences between the BISON simulation and experiment cladding burst conditions (e.g., stress, strain, temperature) that arise from an incomplete characterization of the cladding surface temperature and uncertainty in the cladding creep and failure models. It was determined that improvements to the experiment and to the model were required to adequality represent full-length fuel rod performance.

The cladding burst tests generally lack characterization, and the only data provided for these tests are the cladding geometry, initial and online pressure, and between one to three thermal couple measurements. However, there is no spatial temperature, strain/strain-rate information, or characterization of the void volume - all of which were demonstrated to affect the experimental results. Incorporating the use of an infrared camera to fully characterize the cladding surface temperature during the burst test would be beneficial. This would enable data on surface boundary conditions to be collected continuously as the experiment progresses. The data could be implemented into the fuel performance code rather than implementing data from just a few thermocouples. Additionally, a high-speed camera could also be used in conjunction with digital image correlation analysis to determine the strain and strain rate of the cladding in-situ. Full cladding surface measurements provide data used to evaluate and improve thermal creep and failure models, and by monitoring the cladding deformation behavior and temperature during the experiment, the cladding creep model can be improved and extensively validated.

Lastly, a new model for high-temperature thermal creep of the cladding is currently under development to better capture the impact of microstructural changes on the cladding deformation. This model is being developed by using results from many lower length scale simulations, which are distilled into a simpler form for implementation in the fuel performance code. These model improvements are expected to enable more accurate simulations of the cladding under rupture conditions. Coupling these model improvements to in situ and high-fidelity cladding creep and burst data will enhance BISON's ability to predict LOCA performance, especially in commercial fuel rod applications.

\section{Cladding Rupture Opening Model}

\subsection{Literature Review: Experimental Data Summary}

Historical LOCA fuel performance modeling has only been used to consider fuel rod evolution up to the point where cladding rupture occurs, with no assessment of the post-burst rupture geometry characteristics. These previous analyses have been developed and used specifically to assess the impacts of flow blockage on assembly cooling and to determine the equivalent cladding reacted (ECR). Very little effort has prioritized modeling the burst opening size, as there has been no reason to consider this. However, burnup extension may require the nuclear industry to consider quantifying fuel dispersal. With fuel dispersal in mind, the shape and size of the rupture opening may be an important consideration as fuel fragments are required to be smaller than the rupture opening to physically disperse through the cladding rupture opening. A recent paper by Capps et al. [57] indicates that the size of the burst opening is proportional to the amount of fuel dispersal, and it suggests that large amounts of dispersal required the area of the burst opening to be greater than $\sim 80-100 \mathrm{~mm}^{2}$. Therefore, quantifying the burst opening may offer the potential to minimize fuel dispersal and its consequence. This work aims to develop rudimentary screening criteria to determine how the size of a rupture opening that results from cladding burst. 
There are many ways to measure burst width, length, and area. The burst width and length are the easiest to measure, simply requiring a caliper. This approach has been used for unirradiated material, because hands-on as opposed to measuring through a hot cell window. Irradiated materials are more difficult because they cannot be easily handled. Typically, high quality photos of the sample are taken post-LOCA with an adjacent ruler. The burst width and length are then measured digitally. Burst area is a more complicated measurement because each burst opening is slightly different, but in-general, the burst shape is similar to an ellipse. The easiest approach for unirradiated material is to use a Keyence-3100 structured light scanner to generate a detailed 3D representation of the burst opening. These images can then be used to digitally determine the area of the burst opening. Irradiated materials use the same approach because of the difficulty associated with deploying the Keyence-3100 structured light scanner or a similar system incell.

The data extracted from numerous experimental test programs have historically considered relating the rupture area to the rupture pressure or temperature. This is most evident in NUREG/CR-0344 and the Organization for Economic Co-operation and Development Nuclear Energy Agency (OECD-NEA) FFRD (see Figure 7.2-8 in the OECD FFRD report) report [56]. Both reports propose a generic piece-wise approach to bound the rupture opening as a function of rupture pressure and temperature for unirradiated and irradiated specimens. The models indicate that the largest rupture openings occurred when the rupture pressure was comparable to $-5.5 \mathrm{Mpa}$, the temperature was $825-850^{\circ} \mathrm{C}$, and the data indicate that irradiated cladding typically has larger burst openings than unirradiated cladding. However, there is tremendous scatter in the data and the developed models are grossly conservative. Therefore, a new approach was considered to refine the burst opening model.

A literature search was performed to extract Zircaloy tube burst data and compile it to develop the screening criterion. The literature review evaluated cladding burst tests on different types or Zr-alloy tubes with varying tube geometries. The raw data were evaluated and compared against a number of different parameters, and through this comparison, it was determined that the rupture opening closely tracked with the balloon deformation. The comparisons are shown in Fig. 21 through Fig. 23. Fig. 21 shows that the burst area has a dependency on the balloon geometry. There are some outliers, and most of the outliers are attributed to test rodlets that experience a significant amount of rod bending during the test. Upon further analysis, it can be seen Fig. 22 depicts a comparison similar to that in Fig. 21, except the burst area is replaced by burst length. This comparison has a much stronger relationship, suggesting that the burst length is highly dependent on the balloon geometry. Lastly, Fig. 23a compares the burst width to the burst length. Again, there is a strong relationship between burst width and burst length. An additional step was taken to normalize the burst width data against the cladding's outer diameter. This normalization indicates that the maximum possible burst width corresponds to the cladding's outer diameter. Again, there are a few outliers ( $<10$ data points), however, those data points experienced a significant amount of bending during the test. 


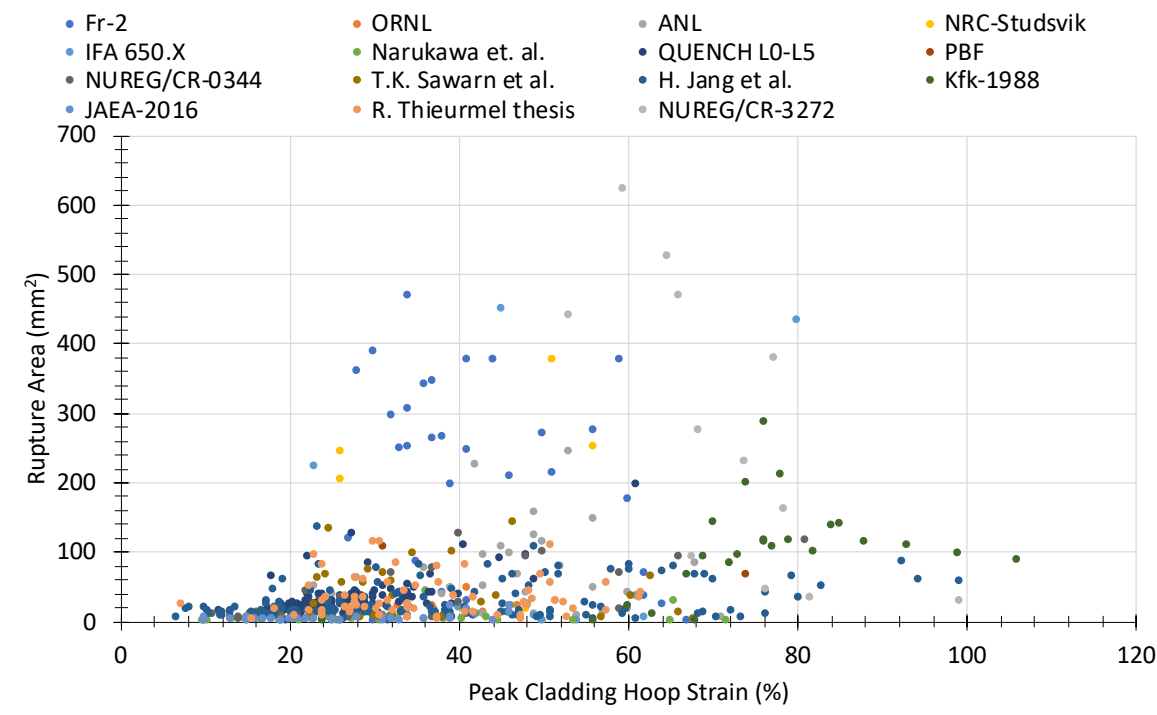

Fig. 21. Cladding burst area as a function of post-LOCA hoop strain [58-86].

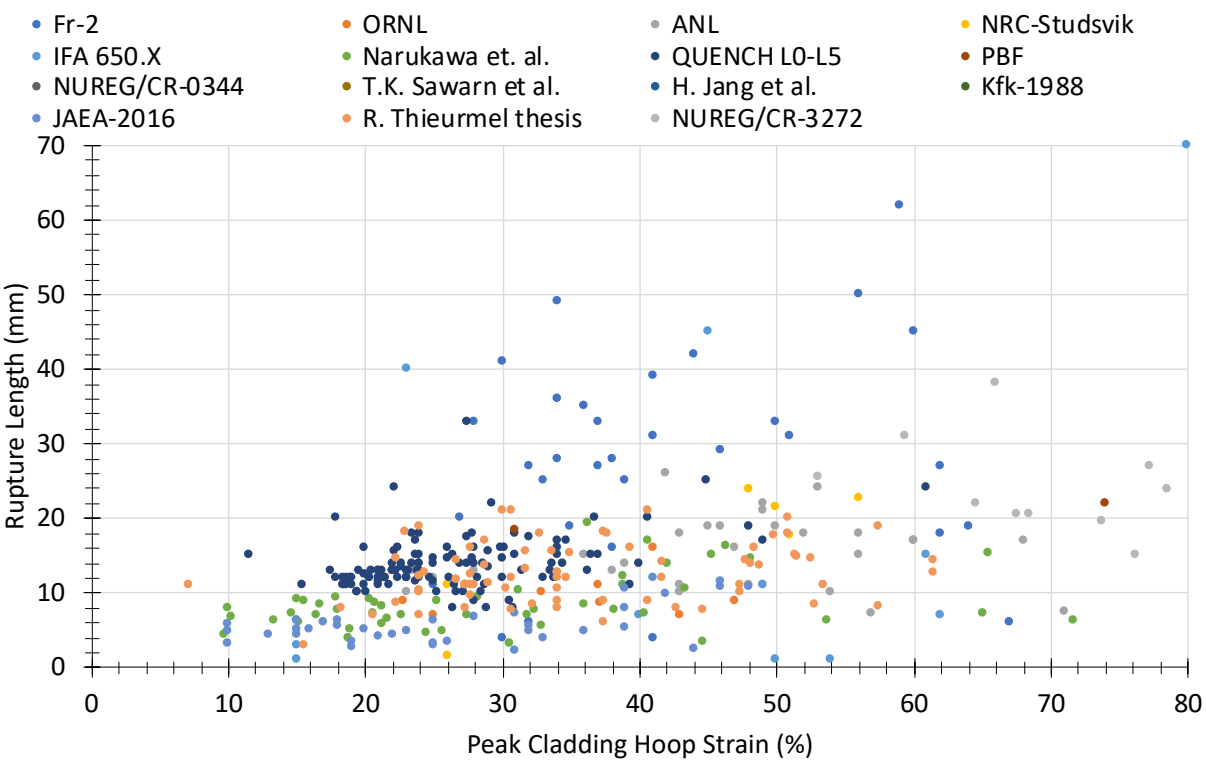

Fig. 22. Cladding burst length as a function of post-LOCA hoop strain [58-86]. 


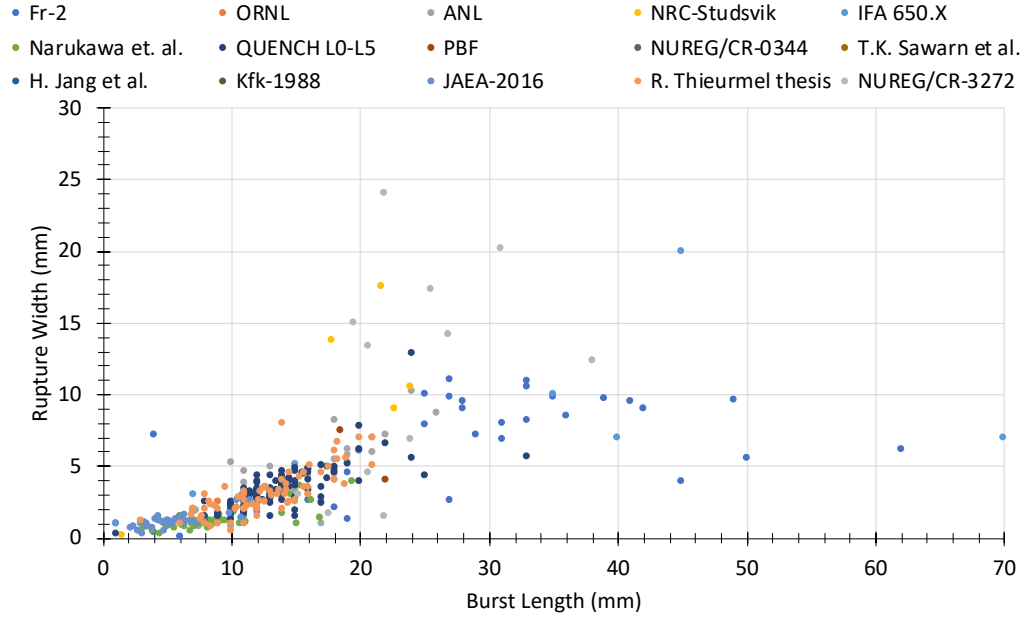

(a)

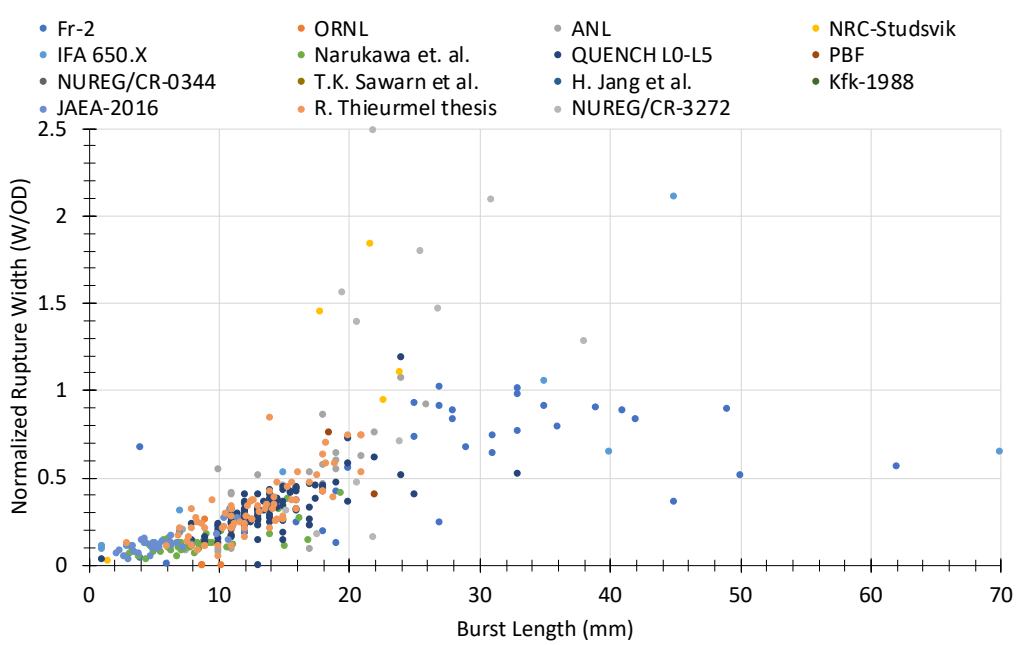

(b)

Fig. 23. Cladding (a) burst width and (b) normalized burst width (burst width / cladding initial outer diameter) as a function of burst length [58-86].

\subsection{Model Development}

Fuel dispersal occurs as a result of pulverized fuel relocating and vacating the cladding through the burst opening. Therefore, it is critical to accurately determine the size of the burst area to calculate dispersal susceptibility. The burst area can be determined by calculating the size and width of the cladding rupture based on the peak balloon strain. This is done by using the compiled data to determine a conservative approximation for the cladding rupture length. The length of the rupture is calculated using the calculated peak cladding hoop strain as an input variable. The relation for the cladding rupture length as a function of is:

$$
L_{b}=C_{1} \cdot\left(\varepsilon_{\text {hoop }}-C_{2}\right)^{C_{3}}-C_{4},
$$

where the cladding rupture length $(\mathrm{mm}), L_{b}$, is calculated using the peak hoop strain $(\%), \varepsilon_{\text {hoop }}$, from the fuel performance simulations and constants from Table 9. Fig. 24 shows the cladding rupture length data as a function of peak hoop strain. Additionally, the average and more conservative, limiting, fits are compared to the experimental data. 
Table 9. Fitting constants derived from literature data to determine burst length as a function of peak hoop strain

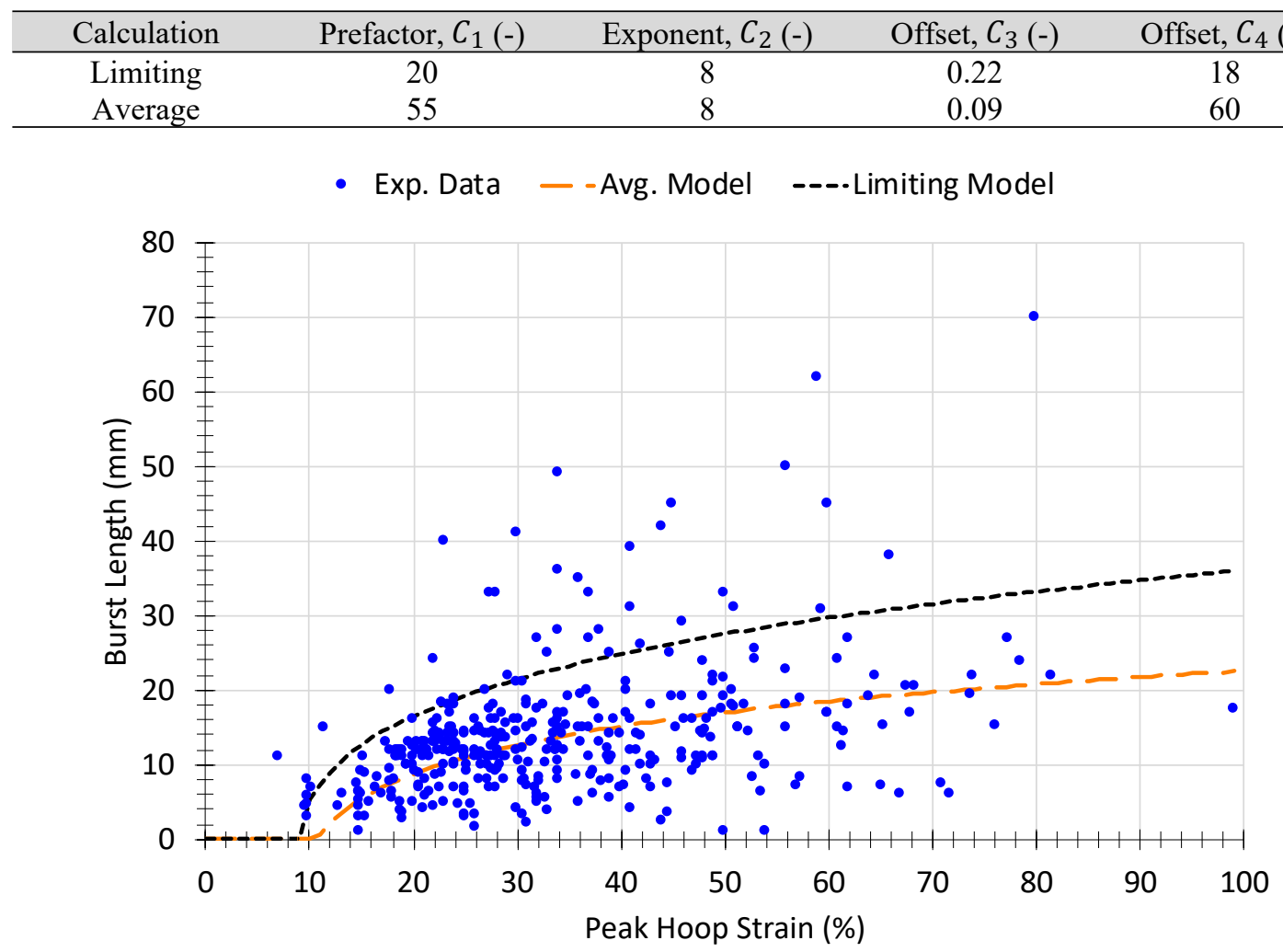

Fig. 24. Comparison of cladding rupture length as a function of peak cladding hoop strain for available literature data and average and limiting models.

The total length of the cladding rupture is used as an input to determine the burst width and subsequently the burst area. As in the process to determine burst length, a function was fit to the burst length vs. the normalized burst width data. The burst width data were normalized, because the cladding data contained different outer diameter geometries. The result of the normalization and fit yielded a cladding rupture opening width $\left(W_{b}\right)$, in mm, of:

$$
\begin{array}{cc}
W_{b}=\left[D_{c}\left(C_{1} \cdot L_{b}^{C_{2}}+C_{3}\right)\right] & L_{b}<43 \mathrm{~mm} \text { for average and } L_{b}<24 \mathrm{~mm} \text { for limited } \\
W_{b}=D_{c} & L_{b} \geq 43 \mathrm{~mm} \text { for average and } L_{b} \geq 24 \mathrm{~mm} \text { for limited }
\end{array}
$$

where $D_{c}$ is the cladding's outer diameter $(\mathrm{mm}), L_{b}$ is the burst length $(\mathrm{mm})$, and constants are determined from fitting and shown in Table 10. Again, there are two sets of constants based on the fitting effort. The fits correspond to the limiting and average conditions from the data. The rupture width only exceeded the cladding's outer diameter when significant rodlet bending occurred, and this only occurred in a very few cases. Therefore, this assumes that the burst width cannot exceed the cladding's outer diameter. The comparison to the limiting and average fits to the experimental data is shown in Fig. 25.

Table 10. Fitting constants derived from literature data to determine burst opening width as a function of burst length

\begin{tabular}{cccc}
\hline Calculation & Prefactor, $C_{1}(-)$ & Exponent, $C_{2}(-)$ & Offset, $C_{3}(-)$ \\
\hline Limiting & 0.055 & 0.92 & -0.01 \\
Average & 0.032 & 0.92 & 0 \\
\hline
\end{tabular}




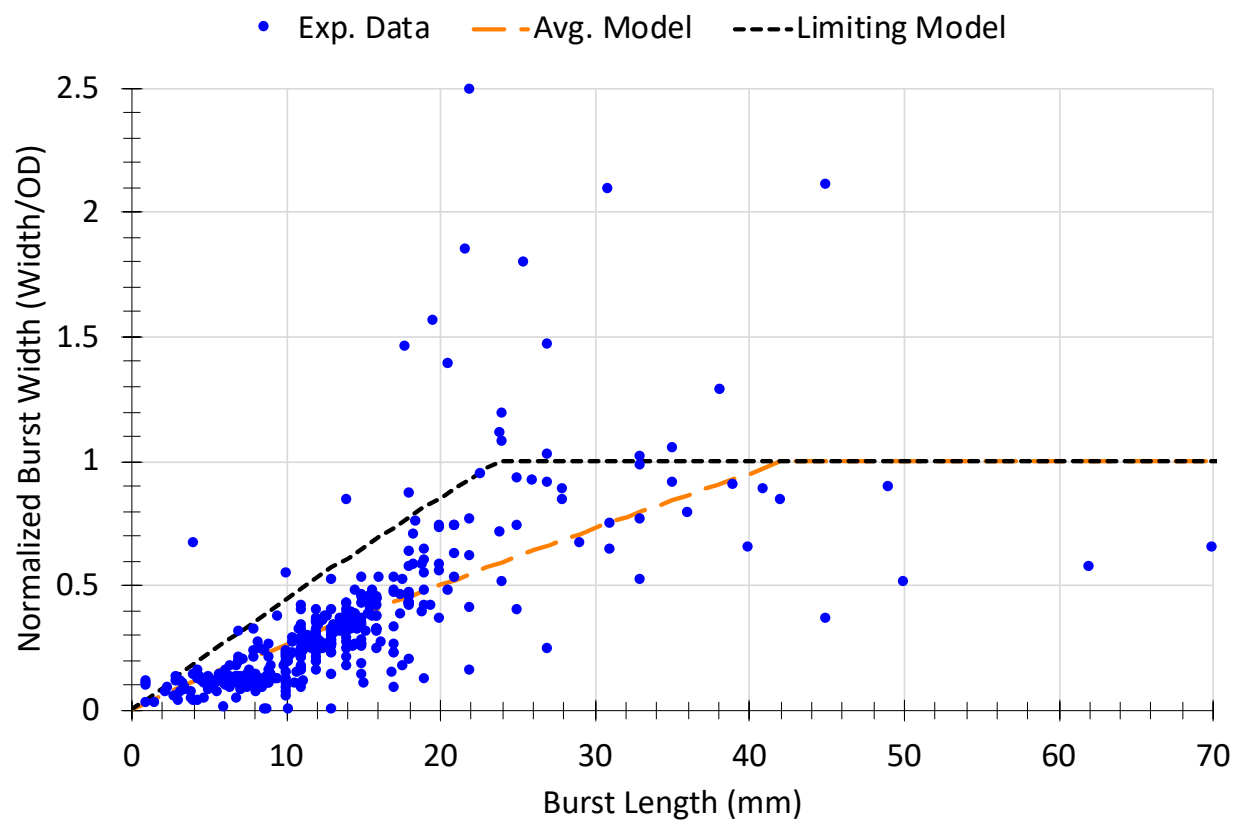

Fig. 25. Comparison of cladding rupture width as a function of rupture length for available literature data and average and limiting models.

The results from the burst length and burst width models can then be used to calculate burst area as a function of hoop strain. However, burst openings have a verity of shapes. The observed shapes tend to take the shape of either a rectangle, ellipse, or a shape comparable to marquise cut diamond (similar to a rhombus), and in some cases, it may be difficult to decide which shape is the most appropriate. Therefore, Fig. 26 compares the calculated burst area for all three shapes to the experimental data. Fig. 26a calculates burst are by using the limiting equations, and Fig. $26 \mathrm{~b}$ calculates burst are by using the average equations. As indicated in Fig. 26a, the rectangle assumption bounds all but a very select few data point, and it would be reasonable to say these data points ( 28 to be exact) are well outside the norm. The ellipse and rhombus assumptions have a much tighter fit to the data. The ellipse is the more conservative than the rhombus, and the rhombus provides the best fit. However, the reality is the shape of the burst likely falls somewhere in-between the two. One could make arguments for each approach; however, the most conservative approach would be to consider the rectangular shape; however, the ellipse and rhombus shape bounds the same amount of data as the rectangular and fits the data better. Furthermore, a large number of the experimental values reported in Fig. 26 conservatively assumes the burst area is calculated by multiplying the burst width and the length. Therefore, this model will assume burst opening is in the shape of a rhombus for the limiting case. 


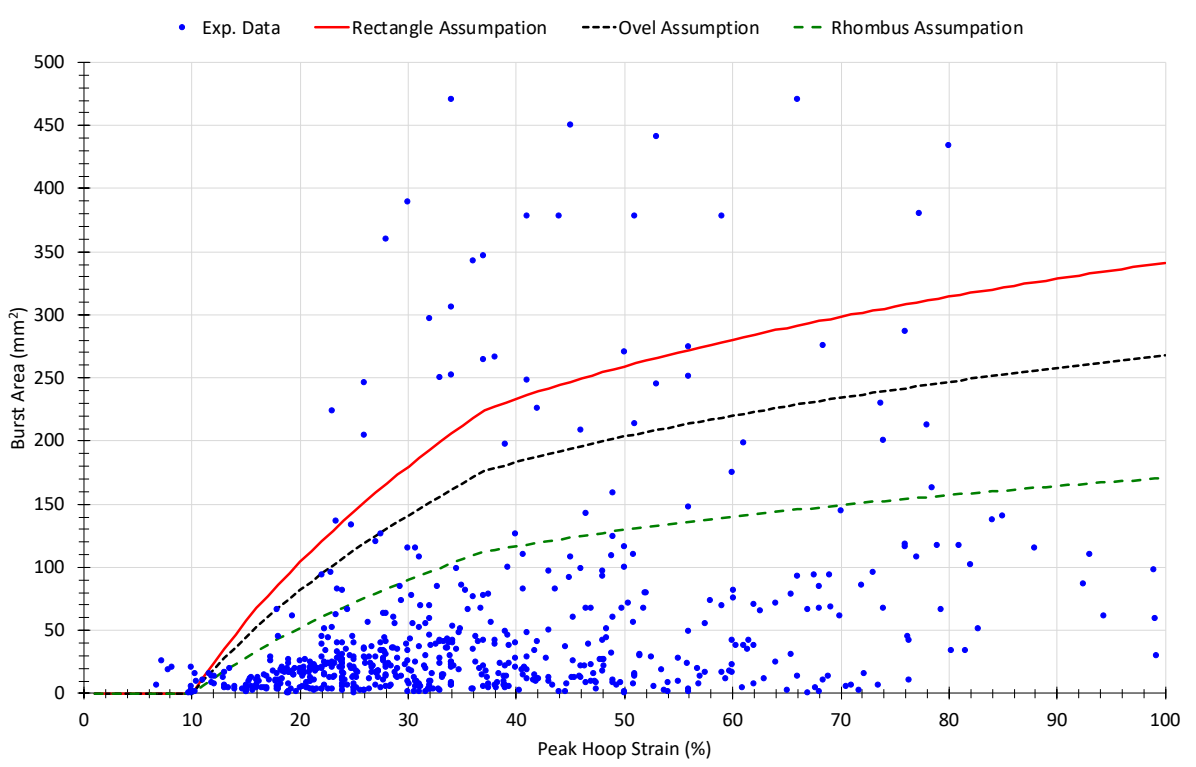

(a)

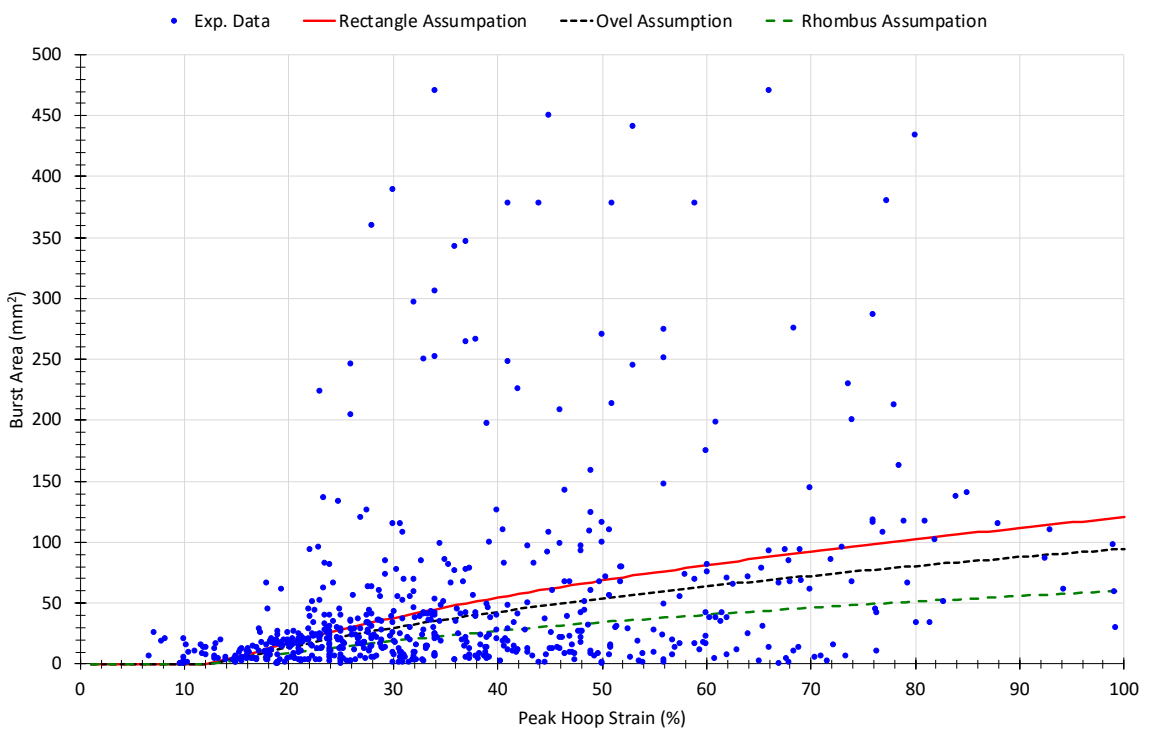

(b)

Fig. 26. Comparison of cladding rupture area as a function of peak cladding hoop strain for available literature data and (a) limiting and (b) average models.

\section{Conclusions}

This work investigated several aspects of cladding and fuel behavior in anticipation of a limited number of tests on high-burnup commercial fuels. The goal of this work was to develop models and calculation methods which may be validated to unirradiated materials and extrapolated to these high-burnup fuels to identify phenomena of interest to best determine the testing parameters of this limited number of samples.

This manuscript documents efforts to determine the role of the fuel stress state in fuel pulverization, demonstrate the difference in conditions between prototypic fuel rods and burst experimental samples, and calculate the cladding rupture geometry to assess fuel dispersal. Although more effort is needed to fully characterize each of these impacts, the results herein can help guide future fuel and cladding testing. 


\section{References}

1. R.L. Williamson, N.A. Capps, W. Liu, Y.R. Rashid, B.D. Wirth, "Multi-Dimensional Simulations of LWR Fuel Behavior in the BISON Fuel Performance Code," JOM (2016). ISSN 1047-4838.

2. R. Williamson, J. Hales, S. Novascone, M. Tonks, D. Gaston, C. Permann, D. Andrs, R. Martineau, "Multidimensional Multiphysics Simulation of Nuclear Fuel Behavior," J. Nucl. Mater. 423 (2012)149-163.

3. R.L. Williamson, K.A. Gamble, D.M. Perez, S.R. Novascone, G. Pastore, R.J. Gardner, J.D. Hales, W. Liu, A. Mai, "Validating the BISON Fuel Performance Code to Integral LWR Experiments," Nucl. Eng. Des. 301 (2016) 232-244. ISSN 0029-5493.

4. C. J. Permann, D.R. Gaston, D. Andrš, R.W. Carlsen, F. Kong, A.D. Lindsay, , ... and R.C. Martineau, "MOOSE: Enabling Massively Parallel Multiphysics Simulation." SoftwareX, (2020)11, 100430.

5. R.L. Williamson, K.A. Gamble, D.M. Perez, S.R. Novascone, G. Pastore, R.J. Gardner, J.D. Hales, W. Liu, A. Mai, "Validating the BISON Fuel Performance Code to Integral LWR Experiments," Nucl. Eng Des. 301 (2016) 232-244, ISSN 0029-5493, https://doi.org/10.1016/j.nucengdes.2016.02.020.

6. R.L. Williamson, G. Pastore, B.W. Spencer, J.D. Hales, T. and Tverberg, "BISON Validation for LOCA and PCMI Behavior Using Measurements from the Halden Reactor Project." United States: N. p., 2017.

7. J.D. Hales, R.L. Williamson, S.R. Novascone, G. Pastore, B.W. Spencer, D.S. Stafford, K.A. Gamble, D.M. Perez, and W. Liu, "BISON Theory Manual: the Equations behind Nuclear Fuel Analysis," United States: N. p., 2016. Web. Doi:10.2172/1374503.

8. S. Yagnik, "Thermal Conductivity Recovery Phenomenon in Irradiated $\mathrm{UO}_{2}$ and (U,Gd) $\mathrm{O}_{2}$," Proc. Int. Top. Mtg. on LWR Fuel Performance, Park City, Utah, 2000.

9. M. Lippens and L. Mertens, High Burnup $\mathrm{UO}_{2}$ and $(\mathrm{U}, \mathrm{Gd}) \mathrm{O}_{2}$ Thermal Diffusivity Measurements and Post-Irradiation Characterizations, EPRI Report TR-106501, 1996.

10. L.J. Siefken, E.W. Coryell, E.A. Harvego, and J.K. Hohorst, SCDAP/RELAP5/MOD3.3 Code Manual: MATPRO-A Library of Materials Properties for Light-Water-Reactor Accident Analysis. Technical Report NUREG/CR-6150, Vol.4, Rev.2, U.S. Nuclear Regulatory Commission, 2001.

11. L.P. Swiler, R.L. Williamson, and D.M. Perez, "Calibration of a Fuel Relocation Model in BISON." In International Conference on Mathematics and Computational Methods Applied to Nuclear Science \& Engineering, Sun Valley, Idaho, May 5-9 2013. American Nuclear Society.

12. G. Pastore, L. Luzzi, V. Di Marcello, and P. Van Uffelen. "Physics-Based Modelling of Fission Gas Swelling and Release in $\mathrm{UO}_{2}$ Applied to Integral Fuel Rod Analysis." Nucl. Eng. Des., 256:75-86, 2013.

13. K. Sakai. The Fuel Creep Test IFA-701: Results after Four Irradiation Cycles. Technical Report HWR-1039, OECD Halden Reactor Project, 2013.

14. K. Sakai, H. Hanakawa, and T. Tverberg. Investigation of Fission Induced Creep of $\mathrm{UO}_{2}$ and Crdoped fuel in IFA-701. Technical Report HWR-1006, OECD Halden Reactor Project, 2011.

15. R. Szoke and T. Tverberg. Update on In-Pile Results from the Fuel Creep Test IFA-701. Technical Report HWR-1092, OECD Halden Reactor Project, 2014.

16. G. Pastore, L. Luzzi, V. Di Marcello, and P. Van Uffelen. "Physics-Based Modelling of Fission Gas Swelling and Release in $\mathrm{UO}_{2}$ Applied to Integral Fuel Rod Analysis." Nucl. Eng. Des., 256:75-86, 2013. 
17. J. K. Fink and L. Leibowitz. "Thermal Conductivity of Zirconium.” J. Nucl. Mater., 226:44-50, 1995.

18. DG Franklin. Zircaloy-4 Cladding Deformation during Power Reactor Irradiation," In Zirconium in the Nuclear Industry. ASTM International, 1982.

19. M. Limbäck and T. Andersson, "A Model for Analysis of the Effect of Final Annealing on the In- and Out-of-Reactor Creep Behavior of Zircaloy Cladding," in Zirconium in the Nuclear Industry:

Eleventh International Symposium, ed. E. Bradley and G. Sabol (West Conshohocken, PA: ASTM International, 1996), 448-468.

20. F. J. Erbacher, H. J. Neitzel, H. Rosinger, H. Schmidt, and K. Wiehr. "Burst Criterion of Zircaloy Fuel Claddings in a Loss-of-Coolant Accident." In Zirconium in the Nuclear Industry, Fifth Conference, ASTM STP 754, D.G. Franklin Ed., 271-283. American Society for Testing and Materials, 1982.

21. N. E. Hoppe. "Engineering Model for Zircaloy Creep and Growth." In Proceedings of the ANS-ENS International Topical Meeting on LWR Fuel Performance, 157-172. Avignon, France, April 21-24, 1991.

22. B. Kochunas, B. Collins, S. Stimpson, R. Salko, D. Jabaay, A. Graham, Y. Liu, K. S. Kim, W. Wieselquist, A. Godfrey, K. Clarno, S. Palmtag, T. Downar, J. Gehin, "VERA Core Simulator Methodology for Pressurized Water Reactor Cycle Depletion," Nucl. Sci. Eng. 185:1 (2017) 217231, DOI: 10.13182/NSE16-39.

23. A. Godfrey, B. Collins, K.S. Kim, R. Montgomery, J. Powers, R. Salko, S. Stimpson, W. Wieselquist, K. Clarno, J. Gehin, S. Palmtag, R. Montgomery, D. Jabaay, B. Kochunas, T. Downar, N. Capps, J. Secker. VERA Benchmarking Results for Watts Bar Nuclear Plant Unit 1 Cycles 1-12. United States: n. p. (2016).

24. A. Godfrey, B. Collins, C. Gentry, S. Stimpson, J. Ritchie, Watts Bar Unit 2 Startup Results with VERA. United States: n.p. (2017). Web. doi:10.2172/1355891.

25. N. Capps, R. Sweet, N. Brown, A. Wysocki, A. Godfrey, B. Collins, S. Lee, N. Szewczyk, S. HoxieKey, "Full Core LOCA Safety for a PWR Containing High Burnup Fuel," Nucl. Eng. Des. (2021), under review.

26. C. M. Allison, G. A. Berna, R. Chambers, E. W. Coryell, K. L. Davis, D. L. Hagrman, D. T. Hagrman, N. L. Hampton, J. K. Hohorst, R. E. Mason, M. L. McComas, K. A. McNeil, R. L. Miller, C. S. Olsen, G. A. Reymann, L. J. Siefken, SCDAP/RELAP5/MOD3.1 Code Manual, Volume IV: MATPRO-a Library of Materials Properties for Light-Water-Reactor Accident Analysis. NUREG/CR-6150, EGG-2720, Idaho National Engineering Laboratory (1993).

27. N. Capps, Y. Yan, A. Raftery, Z. Burns, T. Smith, K. Terrani, K. Yueh, M. Bales, K. Linton, "Integral LOCA Fragmentation Test on High-Burnup Fuel," Nucl. Eng. Des. 367 (2020) 110811 , ISSN 0029-5493.

28. K.H. Yueh, N. Snis, D. Mitchell, C. Munoz-Reja. "Fuel Fragmentation Data Review and Separate Effects Testing," Proceedings of 2014 Water Reactor Fuel Performance Meeting, Sandia, Japan (WRFPM 2014) (2014), 784.

29. A.G. Evans, R.W. Davidge. "The Strength and Fracture of Stoichiometric Polycrystalline $\mathrm{UO}_{2}$." $J$. Nucl. Mater. 33.3 (1969): 249-260.

30. M. Oguma, "Cracking and Relocation Behavior of Nuclear Fuel Pellets during Rise to Power," Nucl. Eng. Des. 76:1 (1983) 35-45, ISSN 0029-5493.

31. C. Bernaudat. "Mechanical Behaviour Modelling of Fractured Nuclear Fuel Pellets." Nucl. Eng. Des. 156.3 (1995) 373-381.

32. D.D. Lanning, C.E. Beyer, and K.J. Geelhood. Frapcon-3 Updates, Including Mixed-Oxide Fuel Properties. The Commission (1997).

33. D.T. Hagrman, MATPRO-A Library of Materials Properties for Light Water Reactor Accident Analysis. MEL, NUREG/CR-6150, EGG-2720 Vol 4 (1995). 
34. Fuel Analysis and Licensing Code: FALCON MOD: Volume 1: Theoretical and Numerical Bases, EPRI Technical Report 1011307 (2004).

35. A. Toptan, J.D. Hales, R.L. Williamson, S.R. Novascone, G. Pastore, and D.J. Kropaczek. "Modeling of Gap Conductance for LWR Fuel Rods Applied in the BISON Code." J. Nucl. Sci Technol. (2020).

36. W. Wiesenack, Summary of the Halden Project LOCA Test Series IFA-650, HPR-380, OECD NEA Halden Reactor Project (2013).

37. L. Lekkonen, LOCA Testing in Halden, the Fourth Experiment: IFA-650.4, HWR-838, OECD Halden Reactor Project (2007).

38. N. Capps, C. Jensen, F. Cappia, J. Harp, K. Terrani, N. Woolstenhulme, D. Wachs, “A Critical Review of High Burnup Fuel Fragmentation, Relocation, and Dispersal under Loss-of-Coolant Accident Conditions," J. Nucl. Mater. 546 (2021), 152750, ISSN 0022-3115, https://doi.org/10.1016/j.jnucmat.2020.152750.

39. B.C. Oberlander, M. Espeland, N.O. Solum, "PIE Results from the High Burnup ( 92 GWd/MTU) PWR Segment after LOCA Testing in IFA 650-4," Proceedings of the EHPG Meeting, Sandefjord, 2011.

40. P. A. C. Raynaud, Fuel Fragmentation, Relocation, and Dispersal during Loss-of-Coolant Accidents, US NRC, Office of Nuclear Regulatory and Research, NUREG-2121 (2012).

41. M. Flanagan, P. Askeljung, A. Purana, Post-Test Examination Results from Integral High Burnup Fueled LOCA Test at Studsvik Nuclear Laboratory, US NRC, Office of Nuclear Regulatory and Research, NUREG-2160 (2013).

42. P. Askeljung, J. Flygare, and D. Minghetti, "NRC LOCA Testing Program at Studsvik, Recent Results on High Burnup Fuel," Proceedings, 2012 Top Fuel Conference, Manchester, United Kingdom.

43. R. L. Williamson, N. A. Capps, W. Liu, Y. R. Rashid, and B. D. Wirth, "Multi-Dimensional Simulations of LWR Fuel Behavior in the BISON Fuel Performance Code," JOM (2016). ISSN $1047-4838$.

44. R. Williamson, J. Hales, S. Novascone, M. Tonks, D. Gaston, C. Permann, D. Andrs, and R. Martineau, "Multidimensional Multiphysics Simulation of Nuclear Fuel Behavior," J. Nucl. Mater. 423 (2012) 149-163.

45. R. L. Williamson, K. A. Gamble, D. M. Perez, S. R. Novascone, G. Pastore, R. J. Gardner, J. D. Hales, W. Liu, and A. Mai, "Validating the BISON Fuel Performance Code to Integral LWR Experiments," Nucl. Eng. Des. 301 (2016) 232-244. ISSN 0029-5493.

46. D. Gaston, C. Newman, G. Hansen, D. Lebrun-Grandie, "MOOSE: Parallel Computational Framework for Coupled Systems of Nonlinear Equations," Nucl. Eng. Des. 239 (2009) 1768-1778 209.

47. R. Williamson, G. Pastore, R. Gardner, K. Gamble, S. Novascone, J. Tompkins, and W. Liu, LOCA Challenge Problem Final Report, CASL-U-2019-1856-000, May 2019.

48. V. Di Marcello, A. Schubert, J. van de Laar, and P. Van Uffelen, "The TRANSURANUS Mechanical Model for Large Strain Analysis," Nucl. Eng. Des., 276 (2014) 19-29.

49. N. Capps, A. Wysocki, A. Godfrey, B. Collins, R. Sweet, N. Brown, S. Lee, N. Szewczyk, and S. Hoxie-Key (2021). "Full Core LOCA Safety Analysis for a PWR Containing High Burnup Fuel." Nucl. Eng. Des. 379. 111194. 10.1016/j.nucengdes.2021.111194.

50. FRAPTRAN: A Computer Code for the Transient Analysis of Oxide Fuel Rod, NUREG/CR-6739 Vol. 1, August 2001.

51. V. Di Marcello, A. Schubert, J. van de Laar, and P. Van Uffelen, "The TRANSURANUS Mechanical Model for Large Strain Analysis," Nucl. Eng. Des., 276 (2014) 19-29.

52. P. A. C. Raynaud, Fuel Fragmentation, Relocation, and Dispersal During Loss-of-Coolant Accidents, US NRC, Office of Nuclear Regulatory and Research, NUREG-2121 (2012). 
53. M. Flanagan, P. Askeljung, and A. Purana, Post-Test Examination Results from Integral High Burnup Fueled LOCA Test at Studsvik Nuclear Laboratory, US NRC, Office of Nuclear Regulatory and Research, NUREG-2160 (2013).

54. J. H. Haberman, LOCA Simulation in the National Research Universal Reactor Program Post irradiation Examination Results for the Third Materials Experiment (MT-3) - Second Campaign. United States (1985). Web. doi:10.2172/1086289.

55. F. J. Erbacher, H. J. Neitzel, and K. Wiehr, Cladding Deformation and Emergency Core Cooling of a Pressurized Water Reactor in a LOCA: Summary Description of the REBEKA Program. Scientific Report KfK 4781, Karlsruhe (1990).

56. K. Pettersson et al., Nuclear Fuel Behaviour in Loss-of-Coolant Accident (LOCA) Conditions, Nuclear Energy Agency of the OECD (NEA), NEA-6846 (2009).

57. N. Capps, C. Jensen, F. Cappia, J. Harp, K. Terrani, N. Woolstenhulme, D. Wachs, "A Critical Review of High Burnup Fuel Fragmentation, Relocation, and Dispersal under Loss-Of-Coolant Accident Conditions," Journal of Nuclear Materials, Volume 546, 2021, 152750, ISSN 0022-3115, https://doi.org/10.1016/j.jnucmat.2020.152750.

58. P. A. C. Raynaud, (2012), Fuel Fragmentation, Relocation, and Dispersal during the Loss-of-Coolant Accident, NUREG-2121.

59. M. Billone, Y. Yan, T. Burtseva and R. Daum, Cladding Embrittlement during Postulated Loss-ofCoolant Accidents, NUREG/CR-6967, USNRC, Washington, DC, USA (2008).

60. N. Capps et al. "Integral LOCA Fragmentation Test on High-Burnup Fuel," Nucl. Eng. Des. (2020), under review.

61. B. C. Oberlander, H. K. Jenssen and M. Espeland, "PIE Results from the High Burnup (83MWd/kg) PWR Segment after LOCA Testing" in IFA 650-5, Loen, Norway, 2008.

62. B. C. Oberlander and H. K. Jenssen, "LOCA IFA650.9: PIE of the $90 \mathrm{MWd} / \mathrm{kg}$ PWR Rod Subjected to a High Temperature Transient," in Enlarged Halden Program Group Meeting, Storefjell, Norway, 2010.

63. B. C. Oberlander, H. K. Jenssen and N. O. Solum, "LOCA IFA650.12: PIE of a BWR Rod Subjected to LOCA Testing in the HBWR," in Halden Program Group Meeting, Halden, Norway, 2012.

64. B. C. Oberländer, H. K. Jenssen, PIE the Rod from LOCA Test IFA-650.13 on High Burnup BWR Fuel, HWR-1095, 2014.

65. B. C. Oberländer, H. K. Jenssen, PIE the Rod from LOCA Test IFA-650.14 on High Burnup BWR Fuel, HWR-1096, 2014.

66. B. C. Oberländer, H. K. Jenssen, PIE on a Pre-Irradiated PWR Fuel Segment LOCA-Tested in IFA 650.15, HWR-1204, 2017.

67. B. C. Oberländer, H. K. Jenssen, Non-Destructive Post Irradiation Examination (PIE) of IFA-650.16, Rod 16 after LOCA Testing Performed in the Halden Reactor, HWR-1241, 2019.

68. E.H. Karb et al., KfK In-Pile Tests on LWR Fuel Rod Behavior during the Heatup Phase of a LOCA, $K f K-3028$, October 1980. ISSN 0303-4003

69. E.H. Karb et al., LWR Fuel Rod Behavior in the FR2 In-Pile Tests Simulating the Heatup Phase of a LOCA, KfK-3346, March 1983. ISSN 0303-4003

70. T. Narukawa and M. Amaya (2016) "The Effect of Oxidation and Crystal Phase Condition on the Ballooning and Rupture Behavior of Zircaloy-4 Cladding Tube-Under Transient-Heating Conditions," J. Nucl. Sci. Tech., 53:1, 112-122, DOI: 10.1080/00223131.2015.1025884

71. T. Narukawa and M. Amaya (2016), "The Effect of Azimuthal Temperature Distribution on the Ballooning and Rupture Behavior of Zircaloy-4 Cladding Tube under Transient-Heating Conditions," J. Nucl. Sci. Tech., 53:11, 1758-1765, DOI: 10.1080/00223131.2016.1158671

72. H. Jang, S.Y. Lee, Y.H. Kim, J.L. Kim, and Y.K. Mok (2018). "Burst Opening Area of HANA-6 Cladding in Simulated LOCA Conditions." Proceedings of the KNS 2018 Fall Meeting, (p. v). Korea, Republic of: KNS.

73. T.K. Sawarn, S. Banerjee, S.S. Sheelvantra, J.L. Singh, and V. Bhasin, "Study of Clad Ballooning and Rupture Behaviour of Indian PHWR Fuel Pins under Transient Heating Condition in Steam 
Environment," J. Nucl. Mater. 495, 2017, 332-342, ISSN 0022-3115, https://doi.org/10.1016/j.jnucmat.2017.08.008.

74. H.M. Chung and T.F. Kassner, (1978), Deformation Characteristics of Zircaloy Cladding in Vacuum and Steam under Transient-Heating Conditions: Summary Report, NUREG/CR-0344

75. J. Stuckert, M. Große, C. Rössger, M. Steinbrück, and M. Walter, (2014). Results of the Commissioning Bundle Test QUENCH-LO Performed under LOCA Conditions. Results of the Commissioning Bundle Test QUENCH-LO Performed under LOCA Conditions. 1-148. $10.5445 / \mathrm{KSP} / 1000037330$.

76. J. Stuckert, M. Große, C. Rössger, M. Steinbrück, and M. Walter (2018). Results of the LOCA Reference Bundle Test QUENCH-L1 with Zircaloy-4 Claddings (SR-7651). 10.5445/IR/1000083067.

77. J. Stuckert, M. Große, C. Rössger, M. Steinbrück, and M. Walter, (2018). Results of the LOCA Bundle Test QUENCH-L2 with M5® Claddings (SR-7677). 10.5445/IR/1000083069.

78. J. Stuckert, M. Große, C. Rössger, M. Steinbrück, and M. Walter, (2018). Results of the LOCA Bundle Test QUENCH-L3 with Optimised ZIRLO ${ }^{\text {TM }}$ Claddings (SR-7737). 10.5445/IR/1000083087.

79. J. Stuckert, M. Große, A. Pshenichnikov, C. Rössger, M. Steinbrück, and M. Walter (2018). Results of the LOCA Bundle Test QUENCH-L4 with Pre-Hydrogenated M5® Claddings (SR-7712). $10.5445 / \mathrm{IR} / 1000083094$.

80. J. Stuckert, M. Große, C. Rössger, M. Steinbrück, and M. Walter, (2018). Results of the LOCA

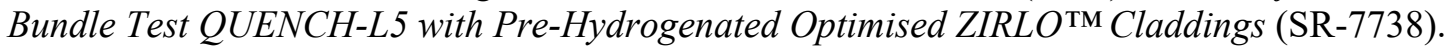
$10.5445 / \mathrm{IR} / 1000083098$.

81. M. E. Markiewicz and F. J. Erbacher. Experiments on ballooning in pressurized and transiently heated Zircaloy-4 tubes. Report KfK 4343, Kernforschungszentrum Karl- sruhe, Germany, 1988.

82. F. J. Erbacher, H. J. Neitzel, and K. Wiehr. Cladding deformation and emergency core cooling of a pressurized water reactor in a LOCA: Summary description of the REBEKA program. Report KfK 4781, Kernforschungszentrum Karlsruhe, Germany, 1990.

83. T. Narukawa and M. Amaya. The effect of oxidation and chrystal phase condition on the ballooning and rupture behavior of Zircaloy-4 cladding tube under transient heating conditions. J. Nucl. Sci. Techn., 53(1):112-122, 2016.

84. M. C. Billone, Y. Yan, T. A. Burtseva, and R. O. Meyer. Cladding embrittlement during postulated loss-of-coolant accidents. Report NUREG/CR-7219, U.S. Nuclear Regulatory Commission, Washington, DC, USA, 2016.

85. C. L. Wilson, C. L. Mohr, G. M. Hesson, N. J. Wildung, G. E. Russcher, B. J. Webb, M. D. Freshley, "LOCA Simulation in NRU Program," NUREG/CR/3272, U.S. Nuclear Regulatory Commission, Washington, DC, USA 1983

86. Ronan Thieurmel. Identification des conditions de rupture fragile des gainages combustibles en alliage de zirconium oxydés sous vapeur d'eau à haute température et trempés sous charge axiale. Matériaux. Université Paris sciences et lettres, 2018. Français. 